Article

\title{
Polystyrene-Supported Acyclic Diaminocarbene Palladium Complexes in Sonogashira Cross-Coupling: Stability vs. Catalytic Activity
}

\author{
Vladimir N. Mikhaylov ${ }^{(D)}$, Viktor N. Sorokoumov, Denis Martin Liakhov ${ }^{(D)}$, \\ Alexander G. Tskhovrebov and Irina A. Balova *(D) \\ Institute of Chemistry, St. Petersburg State University, 7/9 Universitetskaya nab., St. Petersburg 199034, Russia; \\ v.n.mikhaylov@spbu.ru (V.N.M.); v.sorokoumov@spbu.ru (V.N.S.); d.liakhov@spbu.ru or \\ dliakhov@etud.univ-paris8.fr (D.M.L.); a.g.tshovrebov@spbu.ru (A.G.T.) \\ * Correspondence: i.balova@spbu.ru; Tel.: +7-8124286733
}

Received: 9 March 2018; Accepted: 28 March 2018; Published: 2 April 2018

\begin{abstract}
Two types of immobilized on the amino-functionalized polystyrene-supported acyclic diaminocarbene palladium complexes (ADC-Pd ${ }^{\mathrm{II}}$ ) are investigated under Sonogashira cross-coupling conditions. Depending on substituents in the diaminocarbene fragment immobilized ADC-Pd , systems are found to have different catalytic activity and stability regarding Pd-leaching. $\mathrm{Pd}^{\mathrm{II}}$-diaminocarbenes possessing protons at both nitrogen atoms smoothly decompose into $\mathrm{Pd}^{0}$-containing species providing a catalytic "cocktail system" with high activity and ability to reuse within nine runs. Polymer-supported palladium (II) complex bearing $\mathrm{NBn}-\mathrm{C}_{\text {carbene }}-\mathrm{NH}$-moiety exhibits greater stability while noticeably lower activity under Sonogashira cross-coupling. Four molecular ADC-Pd ${ }^{\mathrm{II}}$ complexes are also synthesized and investigated with the aim of confirming proposed base-promoted pathway of ADC-Pd ${ }^{\mathrm{II}}$ conversion through carbodiimide into an active $\mathrm{Pd}^{0}$ forms.
\end{abstract}

Keywords: palladium; cross-coupling; Sonogashira coupling; carbene; polystyrene; catalyst activation; boomerang mechanism; carbodiimide; isocyanide

\section{Introduction}

Carbon-carbon bond forming processes are among the most useful and studied organic transformations [1]. In this regard, current progress in the field of metal-catalyzed cross-coupling reactions has revolutionized synthetic organic chemistry [2]. Highly intense research on the cross-coupling chemistry has resulted in the development of numerous active catalysts [3-5]. The Pd-N,N-heterocyclic carbene (NHC-Pd) complexes have recently emerged as promising air-stable systems, which have been extensively studied in the last few years [6]. The Pd-acyclic diaminocarbene (ADC-Pd) complexes, which exhibit high activity and act as precatalysts in palladium-catalyzed Suzuki-Miyaura, Sonogashira and Mizoroki-Heck cross-coupling processes, become an attractive alternative to the NHC-Pd systems [7-9]. The ADC derivatives possess several advantages [9-11] over NHCs, which are: (a) often higher $\sigma$-donating ability; (b) conformational lability; and (c) wider angle $\mathrm{N}-\mathrm{C}_{\text {carbene }}-\mathrm{N}$ than in the commonly used five-membered NHCs. These are crucial factors affecting catalytic cycles and the stability of various catalytic intermediates [12,13].

Recently, the focus of the research on the cross-coupling reactions has shifted towards the development of not only efficient methods, but also sustainable and economical processes that employ heterogeneous systems [14-16]. Currently, there are several reports on the development of heterogeneous catalysts obtained by the immobilization of NHC-Pd [17-20] on polystyrene [21-25], 
silica gel [26,27], silicon oxide-based mesoporous materials [28-31], nanomagnetite [32,33] and graphene oxide [34-36]. The general approach for the NHC-Pd immobilization is based on the reaction between the $\mathrm{Pd}$ source $\left(\mathrm{Pd}(\mathrm{OAc})_{2}\right.$ or $\left.\mathrm{PdCl}_{2}\right)$ and imidazolium salt, which is covalently attached to the surface of the solid support.

Despite the remarkable progress in the field of heterogeneous catalytic systems, the research that aims to shed light on the nature of the active catalytic form of the heterogeneous catalyst, to distinguish homogeneous catalysis from the heterogeneous one, is still relevant [37-39]. It should be noted that a particular type of catalyst precursor does not guarantee that only one type of catalytically active species is involved in the product formation. The ideas, which deal with the existence of not only heterogeneous or homogenous catalytic systems or so-called "cocktail systems", are actively developing nowadays [40-43]. High catalytic activity of heterogeneous systems may be attributed to both the generation of very active immobilized Pd species under the applied catalytic conditions and/or reversible leaching of the $\mathrm{Pd}$ in the catalytically active form into the solution ("boomerang system") [44-46]. In the latter case, special attention has been paid to the role of the support nature in the process of trapping the catalytically active particles after the reaction [47]. Unfortunately, describing the newly developed heterogeneous systems and their advantages, the authors do not always provide evidence of the true heterogeneous nature of catalysis [48].

We have recently reported a metal-mediated nucleophilic addition to Pd-bound isocyanides as a simple and efficient one-pot approach for the synthesis of ADCs-Pd and their immobilization on the benzhydrylamine resin (BHA@PS) (Scheme 1) [49].

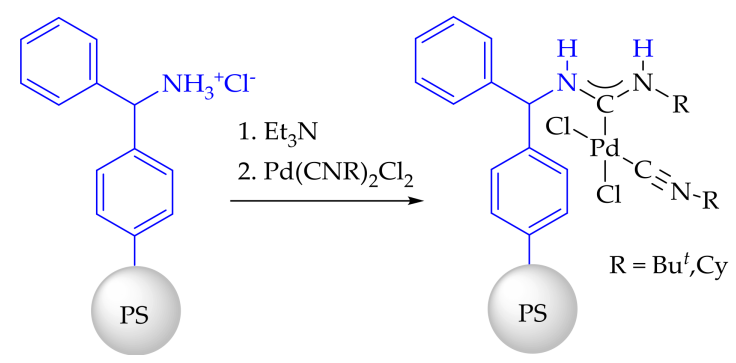

Scheme 1. Synthesis of polystyrene-supported ADC-Pd complexes.

Immobilized in this way, ADC-Pd ${ }^{\mathrm{II}}$ precatalysts exhibited high activity in Sonogashira and Suzuki-Miyaura reactions and a low level of Pd-leaching with the possibility of the recycling. On the other hand, one-step generation and immobilization of ADC-Pd ${ }^{\mathrm{II}}$ complexes allow facile tuning of the structural parameters of the ligand by varying palladium isocyanide complexes or amino-functionalized supports [50]. Aiming at further design of ADCs-Pd ${ }^{\mathrm{II}}$ precatalyst and formulating criteria that can help to obtain heterogeneous systems with high activity and capable of repeated use, we investigate factors affecting their stability and the catalytic activity under the most common cross-coupling reaction conditions.

Here, we report a comprehensive study of polystyrene-supported ADCs-Pd as precatalysts in Sonogashira coupling to determine structural features, i.e., the presence of $\mathrm{NH}$ bound in the $(\mathrm{N}-\mathrm{C}-\mathrm{N})$ carbene fragment, which affect the stability and the catalytic activity. Special attention is devoted to the search of an actual catalytic form in the process that employs immobilized ADC-PdII precatalysts via analysis of both reaction solution (amount of Pd leached from the support during the reaction) and heterogeneous support (presence and the oxidation state of immobilized Pd species before and after the reaction).

\section{Results}

The most convenient way to obtain ADCs-Pd is a metal-mediated addition of N-nucleophiles to $\mathrm{Pd}$-bound isocyanides which results in the formation of diaminocarbene fragment with only three 
points for possible modification: $\mathrm{R}^{1}, \mathrm{R}^{2}$, and $\mathrm{R}^{3}$ (Figure 1) [51]. While $\mathrm{R}^{1}$ comes from the isocyanide ligand, $R^{2}$ and $R^{3}$ correspond to substituents at the nitrogen atom of the nucleophiles. Limitations in isocyanides availability usually restrict the diversity of ADCs-Pd possible to obtain by means of metal-mediated addition to the coordinated isocyanide ligand.

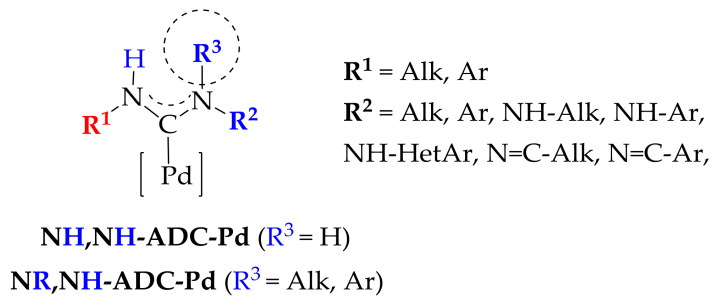

Figure 1. ADC-Pd complex types depending on substituents in the diaminocarbene fragment accessible by metal-mediated addition approach.

Thus, to elucidate diaminocarbene ligand effect on the catalytic activity of ADCs-Pd in the Sonogashira cross-coupling, we use $\mathrm{PdCl}_{2}\left(\mathrm{CNBu}^{t}\right)_{2}$ complex possessing bulky $\mathrm{Bu}^{t}$ group and vary the nature of $\mathrm{N}$-nucleophiles (Figure $1, \mathrm{R}^{2} \mathrm{R}^{3}$ substituents). Two structurally related ADC-Pd with different substitution at nitrogen atoms and steric bulk in the diaminocarbene fragment are chosen for synthesis of polystyrene-supported precatalysts $\mathbf{1}$ and $\mathbf{2}$ (Figure 2).
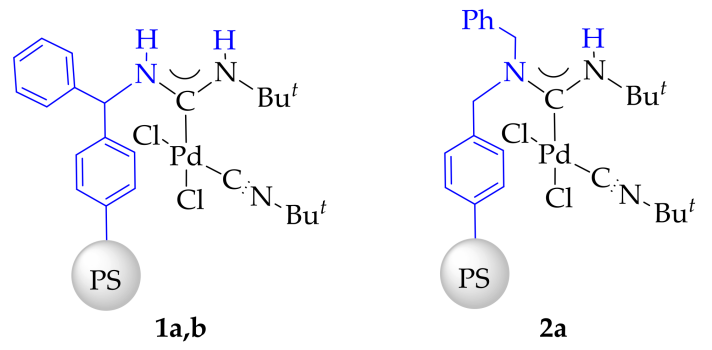

Figure 2. Target precatalyst systems 1 and 2; modification of the resin. Amino groups to ADCs-Pd: a, $30 \%$; and $\mathbf{b}, 80 \%$.

For the synthesis of ADC-Pd ${ }^{\mathrm{II}} \mathbf{1}$, which features two NH fragments at the carbene ligand, we use a previously developed procedure [49]. To synthesize immobilized ADC-Pd ${ }^{\mathrm{II}}$ complexes $\mathbf{2}$ having only one $\mathrm{NH}$ fragment, we prepare a polystyrene derivative which contains the secondary amino groups (Scheme 2). The amount of palladium fastening to the polystyrene during the reaction remained quantitative up to $88 \%$ conversion of surface amino groups. For the catalytic studies, supported precatalysts $\mathbf{1}$ and $\mathbf{2}$ were prepared with a 30\% modification of amino groups (1a and $\mathbf{2 a}$ ), because such degree of modification is suitable for the reliable analysis of the solid phase (infrared spectroscopy (IR) and X-ray photoelectron spectroscopy (XPS)).

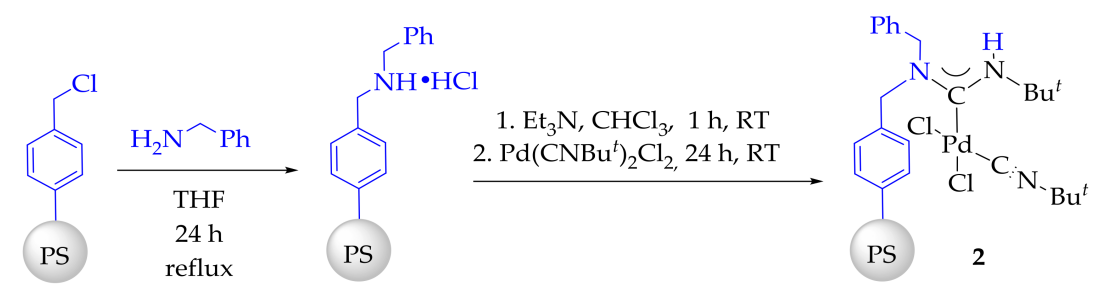

Scheme 2. Synthesis of polystyrene-supported NBn,NH-ADC-Pd ${ }^{\mathrm{II}}$ (2).

The formation of the ADC-Pd ${ }^{\mathrm{II}}$ complexes on the surface of the resin was confirmed by the IR spectroscopy as the common method for this purpose in the case of polystyrene support [48]. 
While IR spectra of $\mathrm{PdCl}_{2}(\mathrm{CNR})_{2}$ features two distinct $\mathrm{C} \equiv \mathrm{N}$ bands due to symmetric and antisymmetric stretching vibrations $\left(2257 \mathrm{~cm}^{-1}\right.$ and $2243 \mathrm{~cm}^{-1}$ for $\left.\mathrm{PdCl}_{2}\left(\mathrm{CNBu}^{t}\right)_{2}\right)$, the product of the metal-mediated nucleophilic addition exhibits only one new band, which corresponds to the $\mathrm{C} \equiv \mathrm{N}$ triple bond [52]. IR spectra of $\mathbf{1 a}, \mathbf{1} \mathbf{b}$ and $\mathbf{2 a}$ exhibit peaks at $2224 \mathrm{~cm}^{-1}, 2220 \mathrm{~cm}^{-1}$ and $2223 \mathrm{~cm}^{-1}$, correspondingly. The presence of only one $\mathrm{C} \equiv \mathrm{N}$ peak indicates on the presence in the structure of one unreacted isocyanide ligand. The longwave shift of the $\mathrm{C} \equiv \mathrm{N}$ peak on the transition $\mathrm{PdCl}_{2}(\mathrm{CNR})_{2} \rightarrow \mathrm{PdCl}_{2}(\mathrm{ADC})(\mathrm{CNR})$ accords with higher $\sigma$-donating ability of the ADC ligand compared to isocyanide [53-57].

To obtain reliable data of the Pd-leaching for supported precatalysts, the reaction for catalytic studies should proceed under the mild conditions [38]. Thus, we chose Sonogashira coupling of highly reactive 1-iodo-4-nitrobenzene (3) with 2-methyl-3-butyn-2-ol (4) which leads to product 5 as a model reaction in a DMF solution at $20^{\circ} \mathrm{C}$ (Scheme 3 ).

The results of nine consecutive reactions with the same precatalyst 1a sample are presented in Figure 3a.

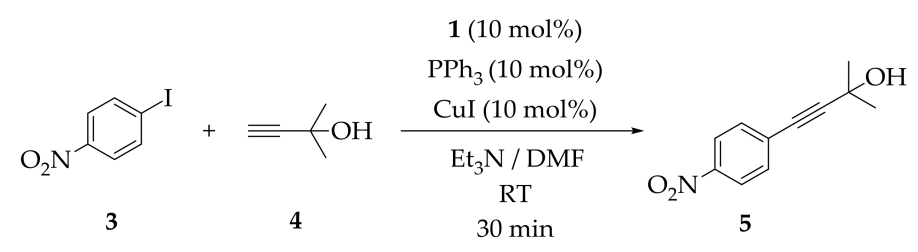

Scheme 3. Model reaction for catalytic studies.

The highest yield after $30 \mathrm{~min}$ in the presence of polystyrene-supported acyclic diaminocarbene palladium complexes 1a was observed for the second run and then gradually decreased for the consequent tests. We anticipate that the lower yield for the first run could be related to the existence of the incubation period, during which inactive $\mathrm{Pd}^{\mathrm{II}}$ form was converted into an active $\mathrm{Pd}^{0}$ catalyst. GC-MS analysis of the reaction mixtures after $24 \mathrm{~h}$ since the supported catalyst was removed (analog of "hot filtration test"), demonstrated virtually full conversion of the starting aryliodide 3 to coupling product 5 for each of nine runs. That indicates that some Pd species leached from the support remain catalytically active in a solution for a long time. AES-ICP data demonstrated that the highest amount of the Pd was leached during the first working run of the precatalyst $1 \mathrm{a}(39.9 \%)$ with a decrease to $0.9 \%$ at the ninth run. Thus, after the eighth run, only $30 \%$ of the initially deposited palladium is left on a support (this corresponds to a polystyrene support with approximately $10 \%$ modification of the surface amino groups to ADC-Pd ${ }^{\mathrm{II}}$ complex). Loading of the supported palladium to the ninth run is reduced to $4.4 \mathrm{~mol} \%$ (from $10 \mathrm{~mol} \%$ in the first run).

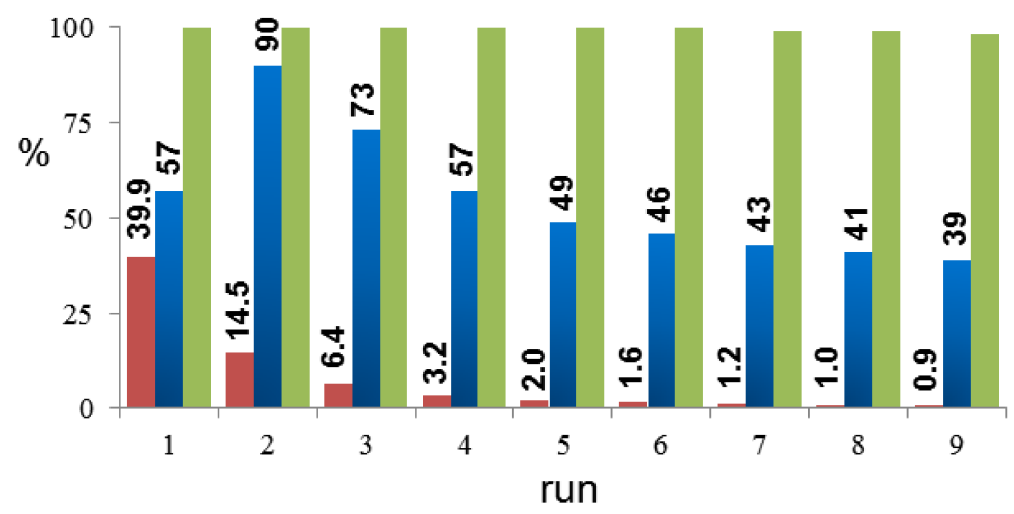

(a)

Figure 3. Cont. 


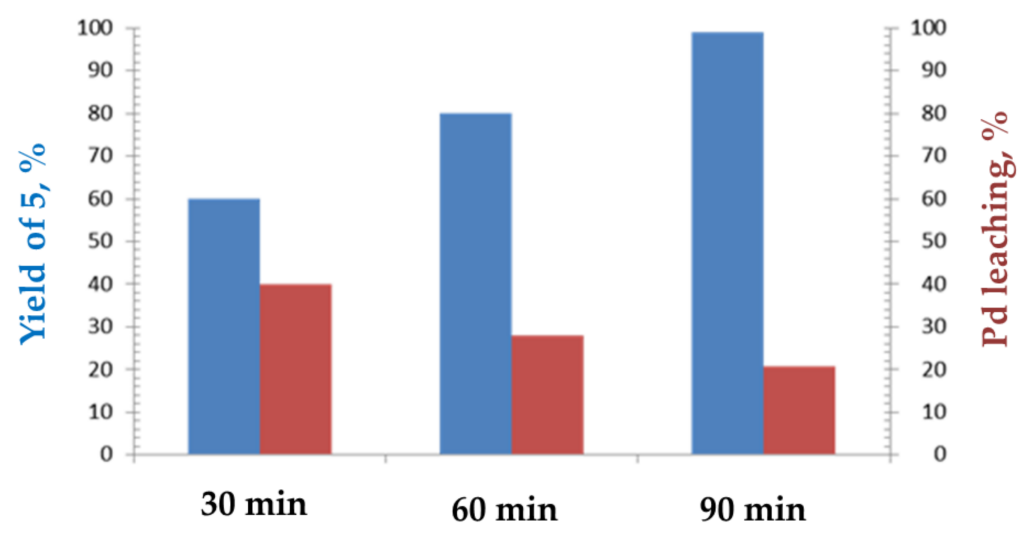

(b)

Figure 3. (a) Pd leaching (red, percent of the initial content), yield of 5 after 30 min (blue), yield of 5 in $24 \mathrm{~h}$ after separation from heterogeneous catalyst (green, "hot" filtration test); and (b) dependence of Pd-leaching upon yield of 5 .

We also found that the conversion of the starting materials in the reactions catalyzed by heterogeneous precatalysts 1a has a significant impact on the palladium leaching. We performed three parallel experiments with precatalysts 1a under the conditions described above for 30, 60 and $90 \mathrm{~min}$ (Figure 3b). An increase in the yield of cross-coupling product 5 from 60\% (30 $\mathrm{min}$ ) to $99 \%$ (90 $\mathrm{min}$ ) was accompanied by a two-time decrease in the palladium content in the solution (from $39.9 \%$ to $20.9 \%$ ), indicating the possibility of reversible palladium leaching into a solution with returning back to the surface while reducing the concentration of the aryliodide.

These results are in a good agreement with previous one [49] obtained for similar reactions using precatalyst system 1 with $10 \%$ degree of modification, which revealed high catalytic activity with a low level of palladium leaching after full conversion of starting materials.

The stability with respect to palladium leaching and catalytic activity of the heterogeneous precatalyst 2a was evaluated under the same conditions, as for precatalyst 1a. The reaction was performed in the cannula-reactor with $10 \mathrm{~mol} \%$ of $\mathrm{ADC}-\mathrm{Pd}^{\mathrm{II}} \mathbf{2 a}$ and repeated six times. The obtained results are summarized in Figure 4.

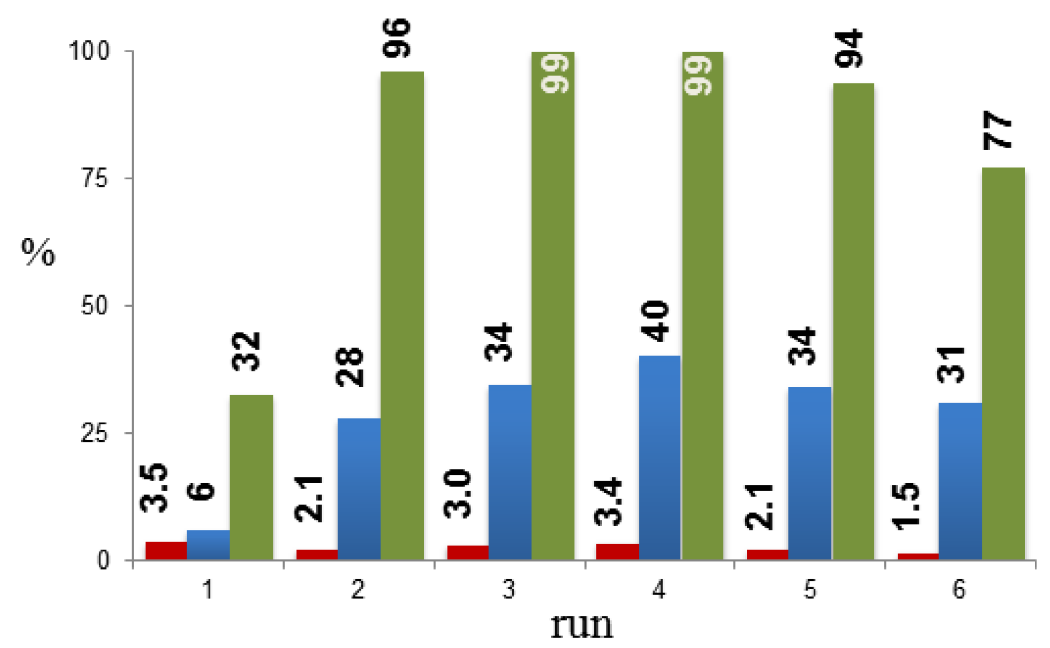

Figure 4. Pd leaching (red, percent of the initial content), yield of 5 after 30 min (blue), yield of 5 in $24 \mathrm{~h}$ after separation from heterogeneous catalyst (green, "hot" filtration test). 
In comparison to precatalyst 1a, the supported ADC-Pd ${ }^{\mathrm{II}}$ complex 2a exhibited higher stability under the same Sonogashira reaction conditions. Thus, leaching of the Pd after the first run was only $3.5 \%, 11$ times less than observed for $1 \mathrm{a}$, which contains two NH-protons in ADC-Pd ${ }^{\mathrm{II}}$ moiety. In this case, the catalytic activity of the precatalyst was also significantly lower, which led to an extremely low conversion of starting materials in the first run after $30 \mathrm{~min}$ The catalytic forms of palladium leached into the solution also showed a lower activity in contrast to precatalyst 1a: $24 \mathrm{~h}$ after the separation of the precatalyst $\mathbf{2 a}$, only $32 \%$ of the product $\mathbf{5}$ was formed (compare the first runs in Figures 3a and 4 ). The highest yield of the product $\mathbf{5}$ after $30 \mathrm{~min}$ of the reaction (40\%) for $\mathbf{2 a}$ was observed only in the fourth run. While all nine runs with precatalyst $1 \mathrm{a}$ led to full conversion of starting materials $24 \mathrm{~h}$ after removing the supported catalyst, for catalyst $\mathbf{2 a}$, a complete conversion was achieved only in the third and fourth runs. That clearly indicates the differences of the "catalytic cocktail" produced by 1a and 2a precatalytic systems. Thus, switching from ADC-Pd having two NH fragments (1a) to ADC-Pd" ${ }^{\mathrm{II}}(\mathbf{2 a})$ dramatically affected their stability and catalytic ability.

Given the high level of Pd-leaching for supported precatalyst 1a in the initial runs, we undertook additional studies. To determine the possible changes of the supported precatalyst, the IR spectrum of 1a after the first run was obtained. It exhibited a new band at $2115 \mathrm{~cm}^{-1}$ with complete disappearance of the band at $2220 \mathrm{~cm}^{-1}$. Such a change in IR earlier [49] was attributed to changes in ligand environment of immobilized ADC-Pd ${ }^{\mathrm{II}}$ complexes under the reaction conditions. We decided to find which component of the reaction mixture causes the band shift. Heating of the starting precatalyst 1a in DMF solution in the presence of 2-methyl-3-butyn-2-ol and 1-iodo-4-nitrobenzene at $70{ }^{\circ} \mathrm{C}$ for $12 \mathrm{~h} \mathrm{did} \mathrm{not} \mathrm{lead} \mathrm{to} \mathrm{any} \mathrm{changes} \mathrm{in} \mathrm{the} \mathrm{IR} \mathrm{spectrum.} \mathrm{At} \mathrm{the} \mathrm{same} \mathrm{time,} \mathrm{the} \mathrm{treatment} \mathrm{of} 1 \mathbf{a}$ with $\mathrm{Et}_{3} \mathrm{~N}$ in DMF at $70{ }^{\circ} \mathrm{C}$ for $1 \mathrm{~h}$ resulted in the emergence of the same new signal at $2115 \mathrm{~cm}^{-1}$. Thus, it was found that the new band appears due to the treatment of $1 \mathbf{a}$ with $\mathrm{Et}_{3} \mathrm{~N}$. It should be noted that we did not find a stretching band in the same region of the IR spectrum for the polystyrene supported precatalyst 2a after the Sonogashira reaction as well after the simple treatment with $\mathrm{Et}_{3} \mathrm{~N}$.

The emergence of this band can be attributed to the formation of carbodiimide, attached to the surface of the polymer. Earlier, Saegusa [58-60] reported that carbodiimides or ketimines could be obtained by the treatment of the acyclic diaminocarbene palladium complexes with $\mathrm{Ag}_{2} \mathrm{O}$ or DBU, correspondingly. In accordance with these findings, we supposed that complex $\mathbf{1}$ undergoes sequential deprotonation and $\beta$-elimination in the presence of such base as $\mathrm{Et}_{3} \mathrm{~N}$, which resulted in the formation of the corresponding carbodiimide (Scheme 4). To implement this carbene-carbodiimide path, ADC ligand must contain both $\mathrm{NH}$-protons. In the case of $\mathbf{2 a}$, carbodiimide cannot be formed this explains why a stretching band around $2115 \mathrm{~cm}^{-1}$ did not appear in the IR spectrum neither after the treatment of $2 \mathrm{a}$ with $\mathrm{Et}_{3} \mathrm{~N}$ nor after the Sonogashira reaction.

The carbene-carbodiimide path should be accompanied by the formation of $\mathrm{Pd}^{0}$, which can potentially self-assemble into catalytically active clusters and nanoparticles. The ease of carbodiimide and $\mathrm{HCl}$ elimination from the certain ADCs-Pd with the formation of $\mathrm{Pd}^{0}$ can be utilized for the catalyst activation in the manner used for commercially available Buchwald precatalysts [61]. The formation of $[\mathrm{Pd}]-\mathrm{C} \equiv \mathrm{NBu}^{t}$ species in the solution was also detected by MS-ESI (in the form of $\mathrm{Pd}_{2} \mathrm{Cl}\left(\mathrm{CNBu}^{t}\right)_{3}$ positive ion). The latter could be potentially adsorbed by the surface amino groups of the polymer through metal mediated coupling with isocyanide ligand that prevents Pd black formation.

Such a process could be a plausible way for regeneration of the heterogeneous catalyst after a run. To confirm the possibility of the capture of dissolved palladium species by the amino-modified polystyrene support, we perform the following experiment. Supported ADC-Pd $\mathbf{1 b}$ ( $80 \%$ conversion of amino groups on support to ADC-Pd complexes) in DMF and initial benzhydrylamine resin (BHA@PS. $\mathrm{HCl}$ ) in the mixture of $\mathrm{Et}_{3} \mathrm{~N} / \mathrm{DMF}$ were placed in two connected syringe-reactors (see Figure 5). 


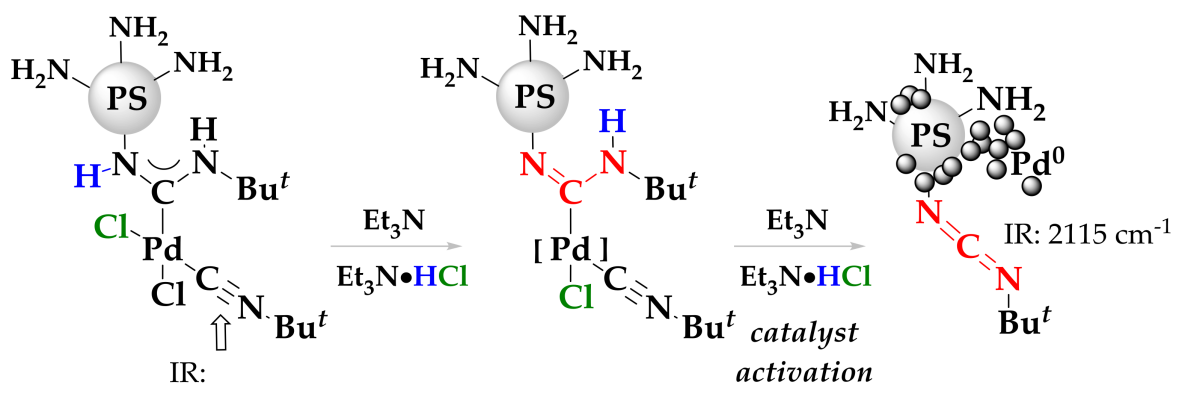

(1a) $2224 \mathrm{~cm}^{-1}$

(1b) $2220 \mathrm{~cm}^{-1}$

Scheme 4. The proposed route for the $\mathrm{Pd}^{0}$ active species generating from supported ADC-Pd ${ }^{\mathrm{II}} \mathbf{1}$.

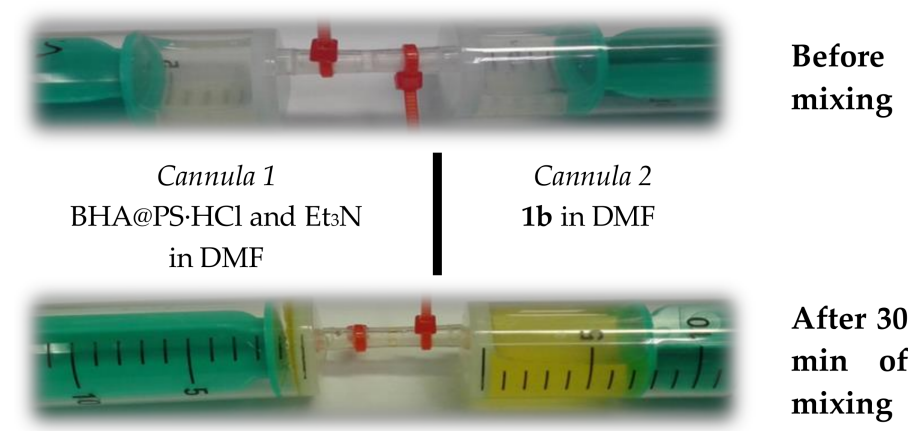

Figure 5. Experiment of a leached palladium binding with benzhydrylamine resin surface.

Further, all liquids were transferred from one cannula to another and then backwards repeatedly for $30 \mathrm{~min}$. This allowed all the potentially dissolved Pd species to interact with the Pd free BHA@PS. The IR spectra for both resins after the experiment looked very similar and showed the presence of an absorption band of carbodiimide fragments (Figure 6). The only observed difference was the weaker intensity of peaks of the resin, which initially did not contain the Pd species. The described experiment indicates on the possibility of the Pd dissolution and its sequential binding on the amine-functionalized resin. Thus, the surface amino groups would act as a stabilizer for leached palladium species. The formed carbene complex on the surface of previously unmodified polymer could gradually decompose and resulted in the emergence of the carbodiimide band.

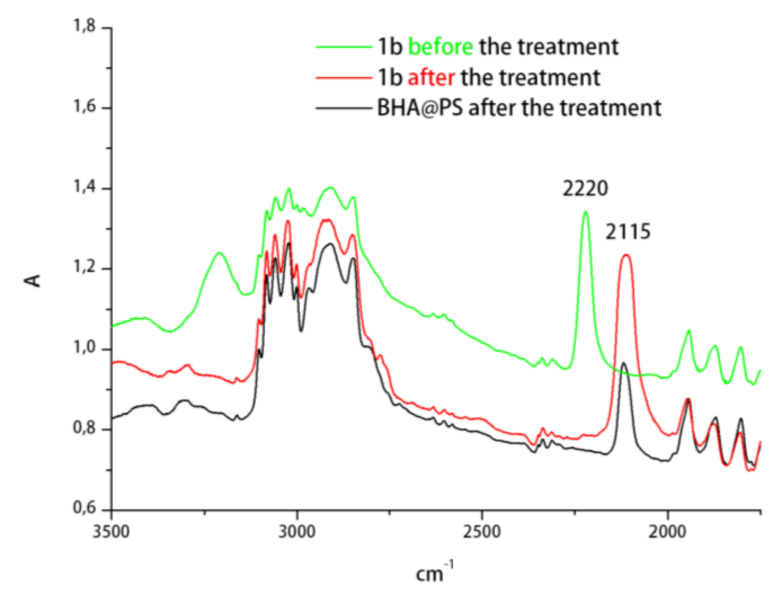

Figure 6. IR spectra of $\mathbf{1 b}$ before (green) and after (brown) the treatment with $\mathrm{Et}_{3} \mathrm{~N}$ and originally Pd-free resign (black) after the solution transfer experiment. 
Both XPS spectra of the resin samples from cannula No1/2 featured peaks, which correspond to $\operatorname{Pd} 3 \mathrm{~d}_{3 / 2}$ and $\mathrm{Pd} 3 \mathrm{~d}_{5 / 2}$. This also confirms the partial transfer of the Pd from one polymer support to another one. Moreover, the comparison of the XPS spectra of starting resin $\mathbf{1 b}$, which contains $\mathrm{Pd}^{\mathrm{II}}$ (peaks with binding energies at $343 \mathrm{eV}$ and $338 \mathrm{eV}$ of $\mathrm{Pd} 3 \mathrm{~d}_{3 / 2}$ and $\mathrm{Pd} 3 \mathrm{~d}_{5 / 2}$ electrons, respectively), with resins from cannula No1 and No2 showed ca. $2 \mathrm{eV}$ shift of the peaks towards lower binding energies, which indicates the formation of $\mathrm{Pd}^{0}$ (Figure 7a). Thus, the treatment of the ADC-PdII complexes bonded with resin surface by $\mathrm{Et}_{3} \mathrm{~N}$ results in the formation of $\mathrm{Pd}^{0}$ species responsible for catalytic activity in Sonogashira coupling. In contrast, the XPS spectrum of $\mathbf{2 a}$ after long-term treatment with $\mathrm{Et}_{3} \mathrm{~N}$, as well as after the Sonogashira coupling conditions, showed no change of the oxidative state of $\mathrm{Pd}^{\mathrm{II}}$ (Figure $7 \mathrm{~b}$ ).

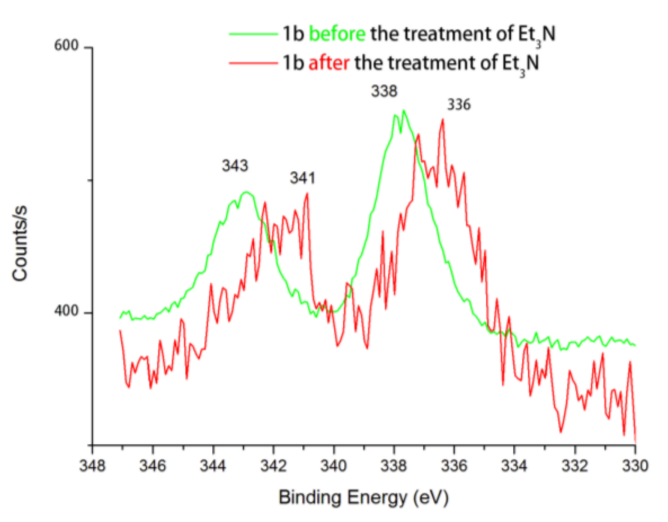

(a)

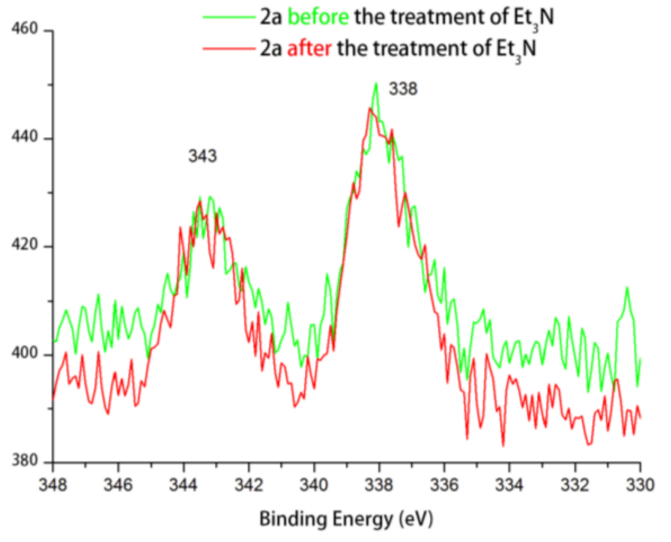

(b)

Figure 7. XPS spectra of the resins $\mathbf{1 b}(\mathbf{a})$ and $\mathbf{2 a}(\mathbf{b})$ before (green) and after (red) the treatment of resin by $\mathrm{Et}_{3} \mathrm{~N}$.

Due to the limitations associated with the structural analysis of the immobilized systems, we prepared molecular ADC-Pd ${ }^{\mathrm{II}}$ complexes (7-9), which are structurally similar to immobilized ADC-Pd ${ }^{\mathrm{II}}$ derivatives $\mathbf{1}$ and $\mathbf{2}$ (Scheme 5). Recently, we reported that the reaction route between benzhydrylamine and $\mathrm{PdCl}_{2}\left(\mathrm{CNBu}^{t}\right)_{2}$ depends on the conditions and results in a formation of either a neutral ADC-Pd ${ }^{\mathrm{II}}$ complex 6 or a cationic analog 11, with bifurcated hydrogen bond, and a neutral amine complex [49].

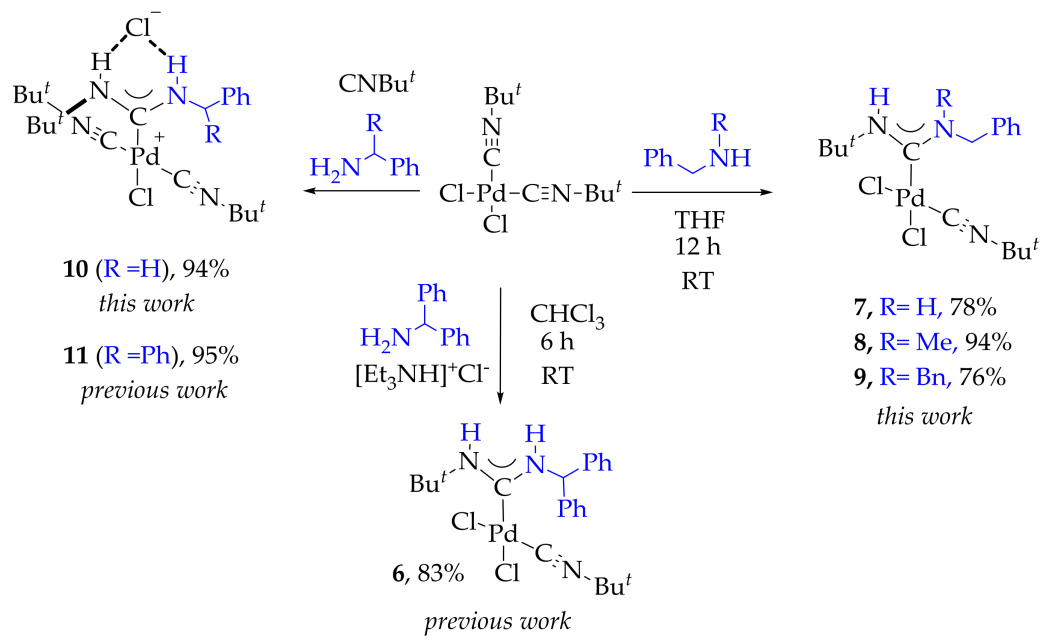

Scheme 5. Synthesis of ADC-Pd ${ }^{\mathrm{II}}$ complexes (6-9) and cationic complexes $\mathbf{1 0}$ and $\mathbf{1 1}$ by an amination of isocyanide complex $\mathrm{PdCl}_{2}\left(\mathrm{CNBu}^{t}\right)_{2}$. 
In contrast with the previously described process [49], the reaction between $\mathrm{PdCl}_{2}\left(\mathrm{CNBu}^{t}\right)_{2}$ and less sterically crowded benzylamine under the same conditions (THF and RT) led to the formation of neutral ADC complex 7 as the only product (Scheme 5).

The structure of 7 was confirmed by X-ray analysis (Figure 8). The coupling between $\mathrm{PdCl}_{2}\left(\mathrm{CNBu}^{t}\right)_{2}$ and $\mathrm{BnNH}_{2}$ in the presence of one equivalent of free $\mathrm{CNBu}^{t}$ results into the formation of cationic complex 10 with $94 \%$ yield (Scheme 5). In the reaction of $\mathrm{PdCl}_{2}\left(\mathrm{CNBu}^{t}\right)_{2}$ with secondary $\mathrm{N}$-methylbenzylamine, we did not expect the formation of cationic complex due to the absence of two $\mathrm{N}-\mathrm{H}$ fragments in ADC-Pd ${ }^{\mathrm{II}}$ complex. This motif is responsible for the formation of three-centered hydrogen bond, which was found to determine the formation of cationic complexes. Neutral ADC-Pd ${ }^{\mathrm{II}}$ complex 8 was also obtained as the only product with $94 \%$ yield.

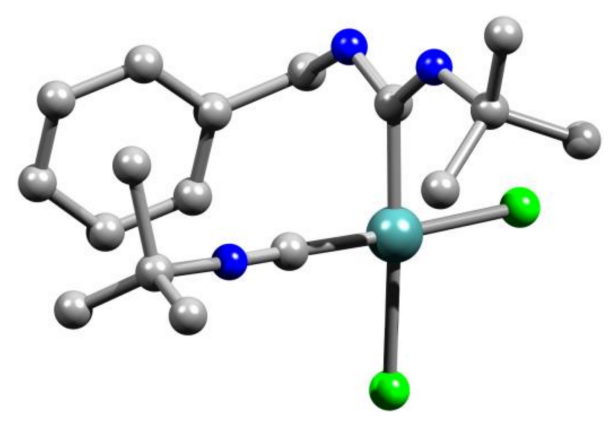

Figure 8. Stick-and-ball representation of the molecular structures of $\mathbf{7}$ in the crystal. Green, cyan, blue and grey spheres represent chlorine, palladium, nitrogen, and carbon atoms, respectively. $\mathrm{H}$ atoms were omitted for clarity.

The X-ray structure of 7 (for full RCA data see SM, Tables S1-S5) displays that, in the solid state, the ADC-fragment in complex 7 exists in syn,syn-configuration. The ADC carbene has an $\mathrm{N}-\mathrm{C}_{\text {carbene }}-\mathrm{N}$ angle of $116.4^{\circ}$ that is typical of unstrained ADC ligands. Complex 7 exhibits slightly distorted square planar geometry around the $\mathrm{Pd}$ center. The $\mathrm{Pd}-\mathrm{C}_{\text {carbene }}$ bond lengths $(1.988 \AA)$ are typical for a single $\mathrm{Pd}-\mathrm{C}$ bond and are comparable to those recently reported for relevant palladium aminocarbene complexes [62,63]. Lengths of $\mathrm{N}-\mathrm{C}_{\text {carbene }}$ bonds were found to be 1.318 and $1.331 \AA$ A which corresponds to diaminocarbene nature of $\mathrm{N}-\mathrm{C}_{\text {carbene }}-\mathrm{N}$ fragment.

${ }^{1} \mathrm{H}$ NOESY experiment revealed that in $\mathrm{CDCl}_{3}$ solution at RT compound 7 exists in the form of two diastereomers $(s y n$, syn and syn, anti, with a ratio $=3 / 1)$. The formation of two distinct isomers is possible due to the hindered rotation around one of the $\mathrm{C}_{\text {carbene }}-\mathrm{N}$ bond (Scheme 6). According to ${ }^{1} \mathrm{H}$ NMR protons of the methylene bridge in the syn,syn-isomer are close to the metal center. These two protons are diastereotopic and exhibit a pronounced difference between their chemical shifts (5.58 ( $\mathrm{dd}$, $J=15.5,7.4 \mathrm{~Hz}, 1 \mathrm{H})$ and $4.91(\mathrm{dd}, J=15.3,3.9 \mathrm{~Hz}, 1 \mathrm{H}))$.

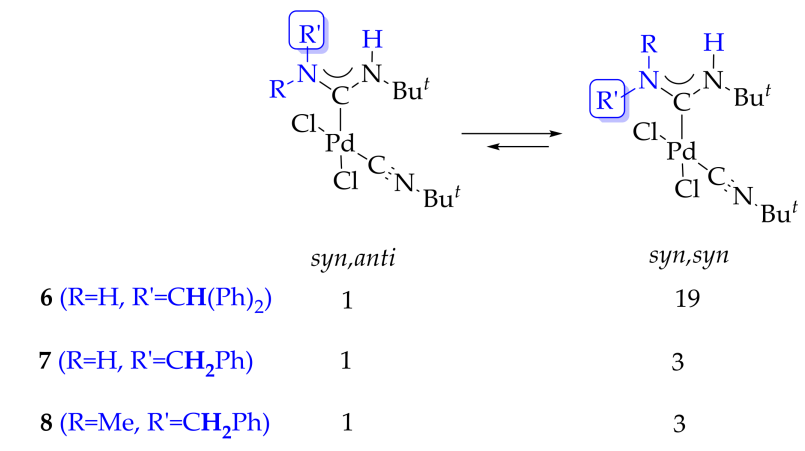

Scheme 6. Ratio between syn,syn and syn,anti conformers for 6, 7 and $\mathbf{8 .}$ 
In comparison with compound 6 where syn,syn/syn, anti ratio is $19 / 1$ in $\mathrm{CDCl}_{3}$ solution (Scheme 6) , compound 7 has significantly less content of syn,syn-isomer due to the steric reasons. We suppose that increased stability of syn,anti-form for benzylamine derivative 7 reduce the possibility of cationic complex with bifurcated hydrogen bond $\mathrm{N}-\mathrm{H} \bullet \bullet \bullet \mathrm{Cl} \bullet \bullet \bullet \mathrm{H}-\mathrm{N}$ generation. A confirmation was obtained by consideration of chemical shifts of $\mathrm{NH}$-protons for $\mathbf{8}$, which bind chloride anion and can be useful for the estimation of the hydrogen bond strength. The ${ }^{1} \mathrm{H}$ NMR spectrum of 8 exhibits peaks, which correspond to NH-protons at $10.39(\mathrm{t}, J=5.8 \mathrm{~Hz})$ and $10.06(\mathrm{~s}) \mathrm{ppm}$. These peaks are shifted to the strong field compared to the signals of NH-protons of $7(10.90(\mathrm{~d}, J=10.3 \mathrm{~Hz})$ and $10.33(\mathrm{~s}) \mathrm{ppm})$. The strong field shift indicates on the weaker acidity of NH-protons and weaker hydrogen bonds $\mathrm{N}-\mathrm{H} \bullet \bullet \bullet \mathrm{Cl} \bullet \bullet \bullet \mathrm{H}-\mathrm{N}$ compared to 7.

Similarly to ADC-Pd ${ }^{\mathrm{II}}$ derivatives 6 and 7 complex 8 exists in $\mathrm{CDCl}_{3}$ solution as a mixture of syn,syn/syn,anti (3/1) isomers. The structure of stereoisomers were confirmed by the 2D NMR (NOESY, ROESY, COSY, HMBS, HSQC). ${ }^{1} \mathrm{H}$ NOESY and ${ }^{1} \mathrm{H}$ ROESY (Figure 9) spectra of the dominant form at $-50{ }^{\circ} \mathrm{C}$ in $\mathrm{CDCl}_{3}$ features a correlation between the neighboring $\mathrm{NH}$-proton and proton from the methyl group (5.93 ppm (NH), $2.97 \mathrm{ppm}\left(\mathrm{CH}_{3}\right)$ ). An experiment was carried out at low temperature to slow down the rotation about the fragment $\mathrm{C}_{\text {carbene }}-\mathrm{N}(\mathrm{Me}) \mathrm{CH}_{2} \mathrm{Ph}$. It should be noted that decreasing the temperature to $-50{ }^{\circ} \mathrm{C}$ shifts the equilibrium toward thermodynamically more preferable syn,syn-isomer $(s y n, s y n / s y n$, anti $=5 / 1)$. We did not find any evidence of the possible rotation of $\mathrm{t}-\mathrm{Bu}-\mathrm{N}-\mathrm{H}$ fragment. Analysis of the ${ }^{1} \mathrm{H}$ NMR spectrum of 9 having symmetrical substitution at one of the carbene nitrogen showed that no rotation of $\mathrm{t}-\mathrm{Bu}-\mathrm{N}-\mathrm{H}$ fragment takes place even in this case.

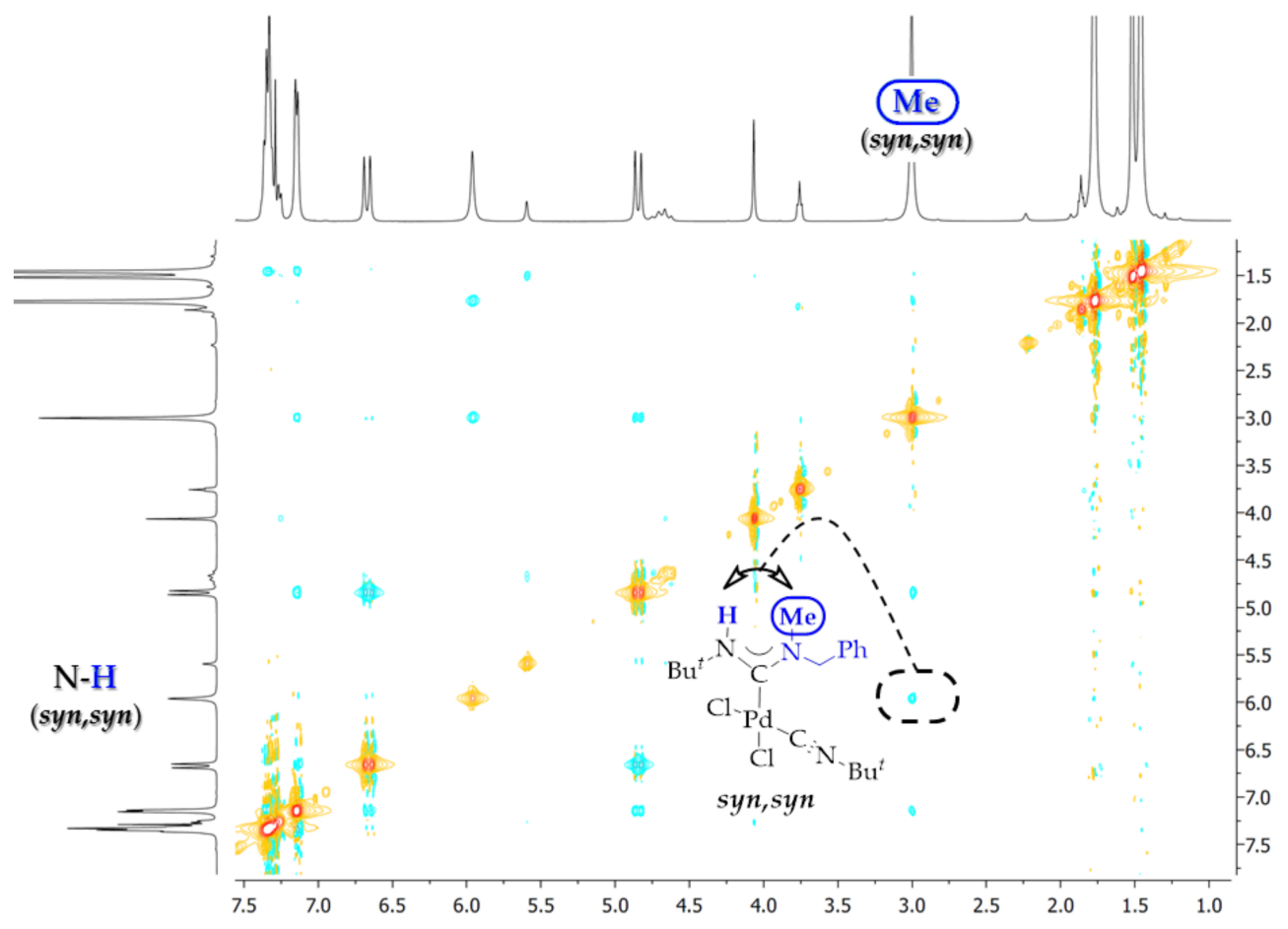

Figure 9. ROESY spectrum of 8 at $-50{ }^{\circ} \mathrm{C}$.

Since we observed the noticeable changes of supported ADC 1a under the treatment of $\mathrm{Et}_{3} \mathrm{~N}$, we compared the stabilities of complexes 6 and 7 in $\mathrm{CDCl}_{3}$ at RT in the presence of 2 equiv. of $\mathrm{Et}_{3} \mathrm{~N}$. The ${ }^{1} \mathrm{H}$ NMR monitoring revealed gradual decrease of $\mathbf{6}$ and $\mathbf{7}$ concentration relatively to the internal standard (1,2-dibromoethane). Remarkably, the decrease of carbene complexes concentration in the presence of triethylamine (the decrease of 6 was noticeably slower then 7) correlates symbatically with the amount of syn,syn-isomer in the solution for $\mathbf{6}$ and 7. Taking into account that the syn,anti-form would likely favor $\mathrm{HCl} \beta$-elimination due to shorter distance between hydrogen of 
$\mathrm{NH}-\mathrm{C}_{\text {carbene }}-\mathrm{NH}$ fragment and chlorine atom in Pd-complex the observed correlation confirms the proposed decomposition route through carbodiimide. Since the syn,syn form can be stabilized by the formation of bifurcated hydrogen bond, we decided to compare stability of 6 and 6 with $\mathrm{Et}_{3} \mathrm{~N} \cdot \mathrm{HCl}$ additive in $\mathrm{CHCl}_{3}$ solutions under the treatment of $\mathrm{Et}_{3} \mathrm{~N}$. We assumed that $\mathrm{Et}_{3} \mathrm{~N} \cdot \mathrm{HCl}$ additive freezes the sin,syn conformation that should prevent the formation of syn,anti-form and, as a result, should slow down the decomposition of the complex. To monitor the changes, we used UV spectroscopy of 6 (Figure 10). Significant grow of the absorption at 304 and $359 \mathrm{~nm}$ was observed after addition of 10 equiv. of $\mathrm{Et}_{3} \mathrm{~N}$ to the solution of 6 in $\mathrm{CHCl}_{3}$. The first order kinetic curve was obtained at $304 \mathrm{~nm}$ (Figure 11a).

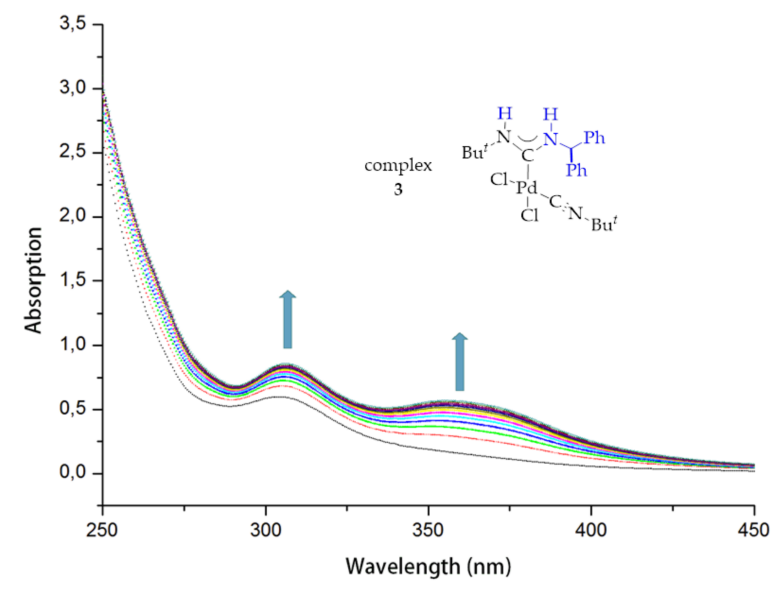

Figure 10. UV-spectra of 6 in $\mathrm{CHCl}_{3}$ recorded during $1000 \mathrm{~s}$ after addition of 10 equiv. of $\mathrm{Et}_{3} \mathrm{~N}$.

Decomposition of the starting material proceeds quickly with $\mathrm{T}_{1 / 2}=286 \mathrm{~s}$. The addition of $\mathrm{Et}_{3} \mathrm{~N} \cdot \mathrm{HCl}$ (10 equiv.) resulted in significant stability enhancement. Thus, half lifetime for the stabilized solution of 6 in $\mathrm{CHCl}_{3}$ treated with 10 equiv. of $\mathrm{Et}_{3} \mathrm{~N}$ was found to be more than 100 times higher, $\mathrm{T}_{1 / 2}=36,806 \mathrm{~s}$ (Figure 11b).

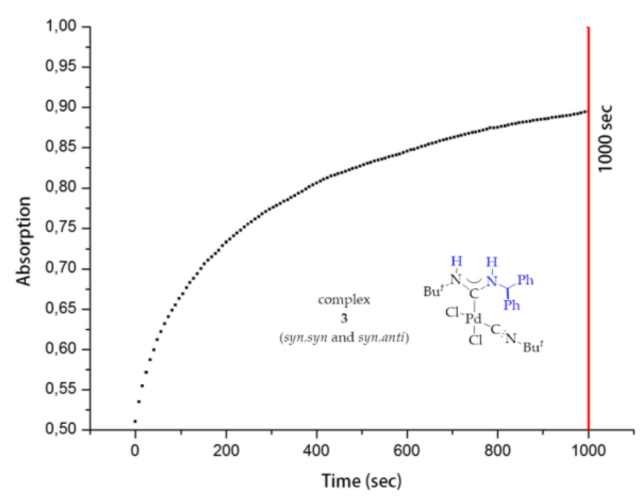

(a)

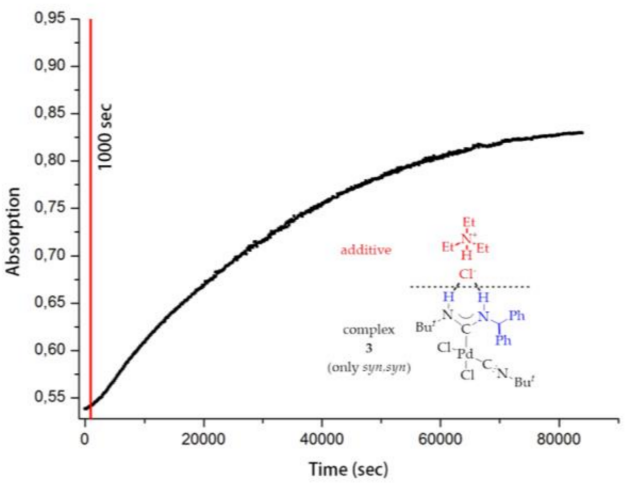

(b)

Figure 11. Kinetic curves of decomposition of: 6 in $\mathrm{CHCl}_{3}$ solution with 10 equiv. of $\mathrm{Et}_{3} \mathrm{~N}(\mathbf{a})$; and 6 with 10 equiv. of $\mathrm{Et}_{3} \mathrm{~N}$ in the presence of 10 equiv. $\mathrm{Et}_{3} \mathrm{~N} \cdot \mathrm{HCl}(\mathbf{b})$.

To prove this decomposition pathway, we studied decomposition of the complexes $\mathbf{8}$ and $\mathbf{9}$, in which the absence of the second NH-proton in the carbene moiety excludes the possibility of HCl- $\beta$-elimination.

As we expected, both complexes ( 8 and 9 ) featured an enhanced stability in the presence of $\mathrm{Et}_{3} \mathrm{~N}$ compared to $\mathbf{6}$ and $\mathbf{7}$. According to UV spectroscopy data, a treatment of complex $\mathbf{8}$ and $\mathbf{9}$ with 10 -fold excess of $\mathrm{Et}_{3} \mathrm{~N}$ did not lead to any changes within $24 \mathrm{~h}$. 


\section{Materials and Methods}

\subsection{General}

Analysis of the reaction mixtures by GC was performed on a Kristall 5000.2 instrument (Chromatec, Yoshkar-Ola, Russia) with a flame ionization detector (FID) (column: Macherey-Nagel MN OptiMA-1 $25 \mathrm{mx} 0.32 \mathrm{~mm} 0.35 \mathrm{mkm}$ ). Leached palladium in the reaction solutions and the palladium content on the modified supports was detected by ICP-AES on a ICPE-9000 instrument (Shimadzu Europa GMBH, Duisburg, Germany). Merrifield resin (1\% cross-linked, 200-400 mesh, $1.0 \mathrm{mmol} / \mathrm{g}$ ) and benzhydrylamine resin hydrochloride ( $2 \%$ cross-linked, 200-400 mesh, ca. $0.6-0.9 \mathrm{mmol} / \mathrm{g}$, (Bachem, Bubendorf, Switzerland)) were used as received. Infrared spectra $\left(4000-200 \mathrm{~cm}^{-1}\right)$ were recorded on a Bruker Tensor 27 instrument as $\mathrm{KBr}$ pellets. UV spectra were recorded on UV-1800 UV-VIS spectrophotometer (Shimadzu Europa GMBH, Duisburg, Germany). NMR spectra were recorded at ambient temperature with a Bruker 400 WB Avance Ш spectrometer (Bruker Ltd. Moscow, 119017, Russia) at $400.13\left({ }^{1} \mathrm{H}\right)$ and $100.61\left({ }^{13} \mathrm{C}\right) \mathrm{MHz}$. Chemical shifts $(\delta)$ are given in ppm relative to the resonances of solvents $\left({ }^{1} \mathrm{H}, \delta 7.26\right.$ for $\mathrm{CDCl}_{3} ;{ }^{13} \mathrm{C}, \delta 77.16$ for $\left.\mathrm{CDCl}_{3}\right)$. Coupling constants $(\mathrm{J})$ are given in Hz. Multiplicities of signals are described as follows: $\mathrm{s}=$ singlet, $\mathrm{d}=$ doublet, $\mathrm{t}=$ triplet, $\mathrm{m}=$ multiplet. The XPS spectrum of the supports was analyzed by X-ray photoelectron spectroscopy (XPS) using a Escalab 250Xi spectrometer (Thermo Fisher Scientific, Waltham, MA, USA) equipped with a monochromatic Al X-ray source. XPS analysis of the supports was performed in the Pd $3 \mathrm{~d}$ region with a $20 \mathrm{eV}$ pass energy, a $0.05 \mathrm{eV}$ step, and a $0.5 \mathrm{~s}$ dwell time. Charge compensation was used, as each sample was nonconductive. All of the binding energy values are calibrated by using $\mathrm{C}(1 \mathrm{~s})=284.6 \mathrm{eV}$ as a reference. A graphical representation of XPS and UV analysis data was performed using Origin 9.0 Software (OriginLab, Northampton, MA, USA). Mass spectra were recorded with a MicrOTOF instrument (ESI) (Bruker Ltd. Moscow, 119017, Russia). The instrument was operated in positive ion mode using an $\mathrm{m} / \mathrm{z}$ range of $50-3000$. The capillary voltage of the ion source was set at $-4500 \mathrm{~V}$ (ESI \pm MS) and the capillary exit at 50-100 V. The nebulizer gas flow was 0.4 bar and drying gas flow was $4.0 \mathrm{~L} / \mathrm{min}$. For ESI, species were dissolved in $\mathrm{MeOH}$. In the isotopic pattern, the most intense peaks are reported. Mass calibration for data system acquisition was achieved using CsI. Elemental analyses were performed on EuroEA3000 Elemental Analyser (Eurovector Srl., Pavia, Italy). Thin-layer chromatography (TLC) was performed using Polygram precoated plastic sheets SIL $\mathrm{G} / \mathrm{UV} 254\left(\mathrm{SiO}_{2}, 0.20 \mathrm{~mm}\right.$ thickness$)$ from Macherey-Nagel. Column chromatography was performed using silica gel (40.0-63.0 nm particle size) from Macherey-Nagel.

All reagents for the Sonogashira reactions were obtained from commercial sources and used as received. DMF was purified via azeotropic distillation with benzene and water, distilled under reduced pressure, and stored under molecular sieves $(4 \AA$ ).

The complexes $\mathrm{PdCl}_{2}\left(\mathrm{CNBu}^{t}\right)_{2}$ [64], 6 [49] and 11 [49] were synthesized according to the literature procedure.

\subsection{Synthesis of 7,8 and 9}

To the suspension of $\mathrm{PdCl}_{2}\left(\mathrm{CNBu}^{t}\right)_{2}(0.069 \mathrm{~g}, 0.20 \mathrm{mmol})$ and THF $(2 \mathrm{~mL})$ in a vial was added the solution of an amine (benzylamine or N-methylbenzylamine or dibenzylamine) $(0.20 \mathrm{mmol})$ in cold THF ( $1 \mathrm{~mL})$ under vigorous stirring. The resulting reaction mixture was stirred at room temperature for $12 \mathrm{~h}$. During the reaction, homogenization of the mixture and subsequent formation of a precipitate were observed. After the stirring, the precipitate was filtered off, washed with diethyl ether $(2 \times 3 \mathrm{~mL})$ and dried at room temperature. Complexes were obtained in pure form and used without further purification.

For ${ }^{1} \mathrm{H},{ }^{13} \mathrm{C}$ NMR and IR spectra of 7, 8, 9 and 10 see SM (Figures S1-S8, S13-S16).

Crystallographic data of $\mathbf{7}$ have been deposited at the Cambridge Crystallographic Data center and allocated the deposition numbers CCDC 1404497. These data can be obtained free of charge via www.ccdc.cam.ac.uk/data_request/cif. 
<smiles>Cl[Te](Cl)(Cl)/C(=N\Br)NCc1ccccc1</smiles>

7

Complex 7 was obtained from benzylamine $(0.022 \mathrm{~g}, 0.20 \mathrm{mmol})$ and $\mathrm{PdCl}_{2}\left(\mathrm{CNBu}^{t}\right)_{2}$ $(0.069 \mathrm{~g}, 0.20 \mathrm{mmol})$ in a yield of $0.070 \mathrm{~g}(78 \%)$. In a solution of $\mathrm{CDCl}_{3}$ at room temperature, the compound is represented by two conformers in equilibrium (isomer ratio 2.8:1 (syn,syn/syn,anti) according to NMR spectroscopy. Major diastereomer. ${ }^{1} \mathrm{H}$ NMR $\left(400 \mathrm{MHz}, \mathrm{CDCl}_{3}\right) \delta 8.08(\mathrm{t}, J=4.4 \mathrm{~Hz}, 1 \mathrm{H}, \mathrm{NH}), 8.97$ $(\mathrm{s}, 1 \mathrm{H}, \mathrm{NH}), 7.53(\mathrm{~d}, J=7.4 \mathrm{~Hz}, 2 \mathrm{H}$, Ar-ortho-H), $7.27(\mathrm{t}, J=7.5 \mathrm{~Hz}, 2 \mathrm{H}$, Ar-meta-H), $7.19\left(\mathrm{t}, J=7.2 \mathrm{~Hz}, 1 \mathrm{H}\right.$, Ar-para-H), $5.58\left(\mathrm{dd}, J=15.5,7.4 \mathrm{~Hz}, 1 \mathrm{H}, \mathrm{CH}_{2}\right), 4.91$ (dd, J $\left.=15.3,3.9 \mathrm{~Hz}, 1 \mathrm{H}, \mathrm{CH}_{2}\right), 1.66\left(\mathrm{~s}, 9 \mathrm{H},\left(\mathrm{CH}_{3}\right)_{3} \mathrm{C}-\mathrm{NH}\right), 1.23\left(\mathrm{~s}, 9 \mathrm{H},\left(\mathrm{CH}_{3}\right)_{3} \mathrm{C}-\mathrm{N} \equiv \mathrm{C}\right) ;{ }^{13} \mathrm{C}$ NMR (101 MHz, $\left.\mathrm{CDCl}_{3}\right) \delta 182.11$ (C carbene), 138.72 (C(Ar)), 128.48 (2C, C-meta-H(Ar) and (C-ortho-H(Ar)), 127.16 (2C, C-para-H(Ar)), $58.82\left(\mathrm{NH}-\mathrm{C}\left(\mathrm{CH}_{3}\right)_{3}\right), 54.79\left(\mathrm{C} \equiv \mathrm{N}-\mathrm{C}\left(\mathrm{CH}_{3}\right)_{3}\right), 52.82$ $\left.\left(\mathrm{CH}_{2}\right), 31.87\left(\mathrm{NH}-\mathrm{C}\left(\mathrm{CH}_{3}\right)_{3}\right), 29.78 \mathrm{C} \equiv \mathrm{NC}(\mathrm{CH})_{3}\right)$ (the signal of the isocyanide carbon atom does not appear); IR (KBr, cm $\left.{ }^{-1}\right): v=3322,2979,2225(\mathrm{C} \equiv \mathrm{N}), 1558,1452,1400,1371,1197,736,699$, HRMS (ESI+, 100V, MeOH): Found 414.0971 [M - Cl]; calculated for $\mathrm{C}_{17} \mathrm{H}_{27} \mathrm{ClN}_{3} \mathrm{Pd}, 414.0928$.

Complex 8 was prepared from N-methylbenzylamine $(0.024 \mathrm{~g}, 0.20 \mathrm{mmol})$ and $\mathrm{PdCl}_{2}\left(\mathrm{CNBu}^{t}\right)_{2}(0.069 \mathrm{~g}, 0.20 \mathrm{mmol})$ in a yield of $0.087 \mathrm{~g}(94 \%)$. In a solution of<smiles></smiles>

8 $\mathrm{CDCl}_{3}$ at room temperature, the compound is represented by two conformers in equilibrium (isomer ratio 2.7:1 (syn,syn/syn,anti)) according to NMR spectroscopy. Major diastereomer. ${ }^{1} \mathrm{H}$ NMR $\left(400 \mathrm{MHz}, \mathrm{CDCl}_{3}\right) \delta 7.32-7.26(\mathrm{~m}, 5 \mathrm{H}, \mathrm{Ar}-\mathrm{H}), 6.35$ (d, $J=15.7 \mathrm{~Hz}, 1 \mathrm{H}, \mathrm{CH}_{2}$ ), 6.03 (s, NH), 5.02 (d, $J=15.8 \mathrm{~Hz}, 1 \mathrm{H}, \mathrm{CH}_{2}$ ), 3.01 (s, $\left.3 \mathrm{H}, \mathrm{NCH}_{3}\right) 1.78\left(\mathrm{~s}, 9 \mathrm{H},\left(\mathrm{CH}_{3}\right)_{3} \mathrm{C}-\mathrm{NH}\right), 1.43\left(\mathrm{~s}, 9 \mathrm{H},\left(\mathrm{CH}_{3}\right)_{3} \mathrm{C}-\mathrm{N} \equiv \mathrm{C}\right) ;{ }^{3} \mathrm{C} \mathrm{NMR}$ $\left(101 \mathrm{MHz}, \mathrm{CDCl}_{3}\right) \delta 181.05$ (C $\left.\mathrm{C}_{\text {carbene }}\right), 135.94$ (C(Ar)), 128.80 (2C, C-meta-H(Ar), 127.89 (C-para-H(Ar)), 127.50 (2C, C-ortho-H(Ar)), $64.34\left(\mathrm{CH}_{2}\right), 59.11\left(\mathrm{NH}-\mathrm{C}\left(\mathrm{CH}_{3}\right)_{3}\right)$, $56.04\left(\mathrm{C} \equiv \mathrm{N}-\mathrm{C}\left(\mathrm{CH}_{3}\right)_{3}\right), 36.50\left(\mathrm{NCH}_{3}\right), 32.23\left(\mathrm{NH}-\mathrm{C}\left(\mathrm{CH}_{3}\right)_{3}\right), 29.88\left(\mathrm{C} \equiv \mathrm{N}-\mathrm{C}\left(\mathrm{CH}_{3}\right)_{3}\right)$ (the signal of the isocyanide carbon atom does not appear); IR $\left(\mathrm{KBr}, \mathrm{cm}^{-1}\right): v=3247,3093,2981,2225$ $(\mathrm{C} \equiv \mathrm{N}), 1589,1576,1451,1397,1372,1198,732$; HRMS (ESI+, $100 \mathrm{~V}, \mathrm{MeOH})$ : Found 428.1129 [M - Cl]; calculated for $\mathrm{C}_{18} \mathrm{H}_{29} \mathrm{ClN}_{3} \mathrm{Pd}, 428.1085$.

Complex 9 was prepared from dibenzylamine $(0.039 \mathrm{~g}, 0.20 \mathrm{mmol})$ and $\mathrm{PdCl}_{2}\left(\mathrm{CNBu}^{t}\right)_{2}(0.069 \mathrm{~g}, 0.20 \mathrm{mmol})$ in a yield of $0.082 \mathrm{~g}(76 \%) .{ }^{1} \mathrm{H} \mathrm{NMR}(400 \mathrm{MHz}$,<smiles>N#C[Ge](Cl)(Cl)/C(CNc1ccccc1)=N\Cc1ccccc1</smiles>

9

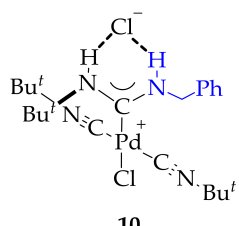

10 $\left.\mathrm{CDCl}_{3}\right) \delta 7.42-7.26(\mathrm{~m}, 10 \mathrm{H}, \mathrm{Ar}-\mathrm{H}), 6.71\left(\mathrm{~d}, J=15.8 \mathrm{~Hz}, 1 \mathrm{H}, \mathrm{CH}_{2}\right), 5.71(\mathrm{~s}, 1 \mathrm{H}$, $\mathrm{NH}), 5.21\left(\mathrm{~d}, \mathrm{~J}=15.8 \mathrm{~Hz}, 1 \mathrm{H}, \mathrm{CH}_{2}\right), 4.50\left(\mathrm{~s}, 2 \mathrm{H}, \mathrm{CH}_{2}\right), 1.54(\mathrm{~s}, 9 \mathrm{H}), 1.50(\mathrm{~s}, 9 \mathrm{H})$; ${ }^{13} \mathrm{C}$ NMR (101 MHz, $\left.\mathrm{CDCl}_{3}\right) \delta 182.91$ (C carbene), 135.83 (C(Ar)), 132.73 (C(Ar)), 129.55 (2C, C-meta-H(Ar), 129.03 (2C, C-meta-H(Ar), 128.55 (C-para-H(Ar)), 128.34 (C-para-H(Ar)), 128.05 (2C, C-ortho-H(Ar)), 126.33 (2C, C-ortho-H(Ar)), $64.30\left(\mathrm{CH}_{2}\right)$, $59.20\left(\mathrm{NH}-\mathrm{C}\left(\mathrm{CH}_{3}\right)_{3}\right), 56.19\left(\mathrm{C} \equiv \mathrm{N}-\mathrm{C}\left(\mathrm{CH}_{3}\right)_{3}\right), 51.72\left(\mathrm{CH}_{2}\right), 31.88\left(\mathrm{NH}-\mathrm{C}\left(\mathrm{CH}_{3}\right)_{3}\right)$, $30.07\left(\mathrm{C} \equiv \mathrm{N}-\mathrm{C}\left(\mathrm{CH}_{3}\right)_{3}\right)$; IR $\left(\mathrm{KBr}, \mathrm{cm}^{-1}\right): v=3294,2982,2225(\mathrm{C} \equiv \mathrm{N}), 1587,1558,1497$, 1454, 1401, 1198, 745, 699; HRMS (ESI+, 100 V, MeOH): Found 504.1374 [M - Cl]; calculated for $\mathrm{C}_{24} \mathrm{H}_{33} \mathrm{ClN}_{3} \mathrm{Pd}, 504.1398$.

Complex 10 was synthesized according to the literature procedure [49]. ${ }^{1} \mathrm{H}$ NMR $\left(400 \mathrm{MHz}, \mathrm{CDCl}_{3}\right) \delta 10.39(\mathrm{t}, J=5.8 \mathrm{~Hz}, 1 \mathrm{H}, \mathrm{NH}), 10.06(\mathrm{~s}, 1 \mathrm{H}, \mathrm{NH}), 7.47(\mathrm{~d}, J=7.4 \mathrm{~Hz}$, $2 \mathrm{H}$, Ar-ortho-H), $7.34(\mathrm{t}, J=7.5 \mathrm{~Hz}, 2 \mathrm{H}$, Ar-meta-H), 7.29-7.22 (m, 1H, Ar-para-H), 4.93 $\left(\mathrm{d}, \mathrm{J}=6.3 \mathrm{~Hz}, 2 \mathrm{H}, \mathrm{CH}_{2}\right), 1.58\left(\mathrm{~s}, 9 \mathrm{H},\left(\mathrm{CH}_{3}\right)_{3} \mathrm{C}-\mathrm{NH}\right), 1.40\left(\mathrm{~s}, 18 \mathrm{H},\left(\mathrm{CH}_{3}\right)_{3} \mathrm{C}-\mathrm{N} \equiv \mathrm{C}\right)$ ); ${ }^{13} \mathrm{C}$ NMR $\left(101 \mathrm{MHz}, \mathrm{CDCl}_{3}\right) \delta 179.11$ (C carbene), $137.60(\mathrm{C}(\mathrm{Ar})), 128.90(\mathrm{C}-$ meta-H (Ar)), 127.76 (C-para-H(Ar)), 127.69 (C-ortho-H(Ar)), $59.89\left(\mathrm{NH}-\mathrm{C}\left(\mathrm{CH}_{3}\right)_{3}\right), 54.10$ $\left(\mathrm{C} \equiv \mathrm{N}-\mathrm{C}\left(\mathrm{CH}_{3}\right)_{3}\right), 53.48\left(\mathrm{CH}_{2}\right), 31.40\left(\mathrm{NH}-\mathrm{C}\left(\mathrm{CH}_{3}\right)_{3}\right), 29.74\left(\mathrm{C} \equiv \mathrm{N}-\mathrm{C}\left(\mathrm{CH}_{3}\right)_{3}\right)$; IR $\left(\mathrm{KBr}, \mathrm{cm}^{-1}\right): v=3198,2983,2224(\mathrm{C} \equiv \mathrm{N}), 1589,1575,1373,1196,746$; HRMS (ESI+, $100 \mathrm{~V}, \mathrm{MeOH})$ : Found 497.1663 [M - Cl]; calculated for $\mathrm{C}_{22} \mathrm{H}_{36} \mathrm{ClN}_{4} \mathrm{Pd}, 497.1658$. 


\subsection{Synthesis and Characterization of Dibenzylamino-Functionalized Polystyrene (DBA@PS)}

Merrifield resin $(1 \mathrm{~g})$ and $15 \mathrm{~mL}$ of absolute THF were placed in a $100 \mathrm{~mL}$ round-bottomed flask. The benzylamine $(0.64 \mathrm{~g}, 6.0 \mathrm{mmol})$ in $10 \mathrm{~mL}$ of absolute THF were then added dropwise to the suspension under vigorous stirring. The resulted suspension was refluxed without stirring for $24 \mathrm{~h}$ (with $\mathrm{CaCl}_{2}$ drying tube). After cooling to room temperature, the resin was filtered off and washed sequentially with $\mathrm{CH}_{2} \mathrm{Cl}_{2}(2 \times 5 \mathrm{~mL}), \mathrm{MeOH}(2 \times 5 \mathrm{~mL}), \mathrm{CH}_{2} \mathrm{Cl}_{2}(2 \times 5 \mathrm{~mL})$ and dried under reduced pressure. The degree of functionalization of the support (complete substitution of chloride atoms by benzylamine) was monitored by Raman spectroscopy (FT-Raman) through both the disappearance of the band at $1265 \mathrm{~cm}^{-1}$ corresponding to the $-\mathrm{CH}_{2-}$ "wag vibration" and the $\mathrm{C}-\mathrm{Cl}$ stretching vibrations $\left(678 \mathrm{~cm}^{-1}\right)$ of the chloromethyl fragment. For DBA@PS IR-spectrum, see Figure S9.

\subsection{Synthesis and Characterization of Immobilized Acyclic Diaminocarbene Palladium (II) Complexes (1,2)}

Benzhydrylamine resin (BHA@PS) or dibenzylamine resin (DBA@PS) (1.5 g) with pre-deblocked aminogroups by triethylamine treatment and $20 \mathrm{~mL}$ of $\mathrm{CHCl}_{3}$ were placed in a $100 \mathrm{~mL}$ one-necked round-bottomed flask equipped with a magnetic stirrer. The resulting suspension was stirred for $30 \mathrm{~min}$. Then, the required amount (depending on the target degree of modification) of $\mathrm{PdCl}_{2}\left(\mathrm{CNBu}^{t}\right)_{2}$ in $5 \mathrm{~mL}$ of $\mathrm{CHCl}_{3}$ was added. Stirring at room temperature was continued for $24 \mathrm{~h}$. The resulting modified resin was filtered, washed with $\mathrm{CHCl}_{3}(3 \times 5 \mathrm{~mL})$ and dried under reduced pressure. The filtrate and the modified resin were analyzed by atomic-emission spectroscopy with inductively coupled plasma to determine the palladium content.

Complex 1a: $0.075 \mathrm{mmol}[\mathrm{Pd}] / \mathrm{g}$. Obtained from $39.7 \mathrm{mg}$ of $\mathrm{PdCl}_{2}\left(\mathrm{CNBu}^{t}\right)_{2}$ and $1.5 \mathrm{~g}$ of polystyrenebenzhydrylamine resin (BHA@PS).

Complex 1b: $0.481 \mathrm{mmol}[\mathrm{Pd}] / \mathrm{g}$. Obtained from $197.5 \mathrm{mg}$ of $\mathrm{PdCl}_{2}\left(\mathrm{CNBu}^{t}\right)_{2}$ and $1.5 \mathrm{~g}$ of polystyrenebenzhydrylamine resin (BHA@PS).

Complex 2: $0.475 \mathrm{mmol}[\mathrm{Pd}] / \mathrm{g}$. Obtained from $197.5 \mathrm{mg}$ of $\mathrm{PdCl}_{2}\left(\mathrm{CNBu}^{t}\right)_{2}$ and $1.5 \mathrm{~g}$ of dibenzylamine resin(DBA@PS).

For IR spectra of 1a, $\mathbf{1 b}$ and 2a, see Figures S10-S12, respectively.

\subsection{The General Procedure for the Sonogashira Reaction Using Heterogeneous Precatalysts:}

The polystyrene-supported acyclic diaminocarbene palladium (II) complex (1 or $\mathbf{2})$ was placed in the volume of the cannula-reactor (a plastic syringe for $10 \mathrm{~mL}$ with a plastic filter disc on the bottom to prevent a loss of the heterogeneous material). DMF $(2 \mathrm{~mL})$ was pumped into the reactor volume and the suspension was kept for $10 \mathrm{~min}$. After swelling of the support, the residual DMF was removed from the volume of the cannula-reactor by a piston push. The reacting components were then pumped into the cannula-reactor as an aliquot solution containing 1-iodo-4-nitrobenzene $(62.25 \mathrm{mg}, 0.250 \mathrm{mmol})$, 2-methyl-3-butyn-2-ol (31.5 mg, $0.375 \mathrm{mmol}), \mathrm{Et}_{3} \mathrm{~N}$ (101 mg, $\left.1.00 \mathrm{mmol}\right), \mathrm{CuI}(4.7 \mathrm{mg}, 0.025 \mathrm{mmol})$, $\mathrm{PPh}_{3}(6.5 \mathrm{mg}, 0.025 \mathrm{mmol})$ and $1.5 \mathrm{~mL}$ of DMF (DMF contained dodecane $(12.5 \mathrm{mmol} / \mathrm{L}$ ) as the internal standard for GC). The reaction mixture was stirred at room temperature for $30 \mathrm{~min}$. Then, the reaction solution was removed from the reactor volume by a piston push. The support in the reactor was washed with DMF $(3 \times 4 \mathrm{~mL})$ before the next run. Further, new aliquot solution with reacting components was pumped into the cannula-reactor, and the repeated runs were performed. After each reaction, the reaction mixtures, immediately after the catalyst separation, were analyzed by gas chromatography with a flame ionization detector (FID) to determine both the conversion of the starting material and the yield of the product. The next time, the reaction mixture was analyzed after $24 \mathrm{~h}$ stirring at room temperature. All reaction mixtures were analyzed by atomic-emission spectroscopy with inductively coupled plasma (ICP-AES) to determine the content of the leached palladium in the reaction solution. Sample preparation for the ICP-AES analysis included the acid decomposition of the dry residue of the reaction solution with a mixture of $\mathrm{HNO}_{3}-\mathrm{H}_{2} \mathrm{O}_{2}$ under boiling conditions. 


\subsection{Kinetic Studies of 6, 8 and 9 Decomposition}

Stock solution of complexes 6 and 8 were prepared as follows: $9.5 \mathrm{mg}$ of $\mathbf{6}$ were dissolved in $4.6 \mathrm{~mL}$ of $\mathrm{CHCl}_{3}$ and $4 \mathrm{mg}$ of 8 were dissolved in $1.88 \mathrm{~mL}$ of $\mathrm{CHCl}_{3}$ to obtain solutions with $\mathrm{c}=0.00392 \mathrm{~mol} / \mathrm{L}$. Working solutions for UV spectra recording were prepared by the addition of $250 \mu \mathrm{L}$ of stock solutions to $2.5 \mathrm{~mL}$ of $\mathrm{CHCl}_{3}$. Kinetic studies were performed with working solutions of $\mathbf{6}$ and $\mathbf{8}$ after the addition of $250 \mu \mathrm{L} \mathrm{Et}_{3} \mathrm{~N}$ solution in $\mathrm{CHCl}_{3}(\mathrm{c}=0.0392 \mathrm{~mol} / \mathrm{L})$ or $250 \mu \mathrm{L}$ of $\mathrm{Et}_{3} \mathrm{~N} \cdot \mathrm{HCl}: \mathrm{Et}_{3} \mathrm{~N}(1: 1)$ solution in $\mathrm{CHCl}_{3}(\mathrm{c}=0.0392 \mathrm{~mol} / \mathrm{L})$.

\section{Conclusions}

Our scrutinizing ADCs-Pd immobilized on the polystyrene support shows that $\mathrm{Pd}^{\mathrm{II}}$-diaminocarbene complex bearing protons at both nitrogen atoms smoothly decomposes through base-promoted carbene-carbodiimide pathway into $\mathrm{Pd}^{0}$-containing species leading to a "cocktail system" with high catalytic activity in the Sonogashira cross-coupling. Owing to the excess of free amino groups on the surface of polystyrene support, a significant amount of leached palladium can be recovered from the solution after the reaction, providing a "boomerang" system with a high capacity to reuse. Polymer-supported palladium (II) complex bearing $\mathrm{NR}-\mathrm{C}_{\text {carbene }}-\mathrm{NH}$-moiety exhibits greater stability, which is associated with the inability to the carbodiimide formation by $\mathrm{HCl} \beta$-elimination and active $\mathrm{Pd}^{0}$-containing species generation. As a result, this type of supported complex displaysd lower activity under Sonogashira cross-coupling conditions. Our findings show the principally new route for $\mathrm{Pd}^{0}$-species generation and stabilization, and casts light on the nature of the catalysis for $\mathrm{Pd}^{\mathrm{II}}$-complexes with different diaminocarbene ligand. On the other hand, the ease of carbodiimide and $\mathrm{HCl}$ elimination from the certain ADCs-Pd with the formation of $\mathrm{Pd}^{0}$ can be utilized for the catalyst activation in the manner used for commercially available Buchwald precatalysts.

Supplementary Materials: The following are available online at http:/ /www.mdpi.com/2073-4344/8/4/141/s1, Tables S1-S5: Crystallographic data, Figures S1-S8: NMR spectra, Figures S9-S16: IR spectra.

Acknowledgments: This study was supported by Saint Petersburg State University (project 12.40.515.2017). V.N.M. is grateful to the Russian Foundation for Basic Research (research project for young scientists No. 16-33-00659 mol_a). The research was carried out by using the equipment of Resource Centers of Saint Petersburg State University Science park: Centre of Magnetic Resonance, Chemistry Educational Centre, Centre for Chemical Analysis and Materials Research, Centre for X-ray Diffraction Studies (special thanks to Suslonov Vitaly for the help with structure elucidation), Center of Physical methods of surface investigation.

Author Contributions: V.N.M. and V.N.S. conceived and designed all experiments; V.N.M. and D.M.L. performed the experiments; V.N.S., V.N.M. and I.A.B. analyzed and discussed all experimental data; and V.N.M., V.N.S., A.G.T. and I.A.B. were responsible for manuscript and Supplementary Materials preparation.

Conflicts of Interest: The authors declare no conflict of interest.

\section{References}

1. Jana, R.; Pathak, T.P.; Sigman, M.S. Advances in Transition Metal (Pd,Ni,Fe)-Catalyzed Cross-Coupling Reactions Using Alkyl-organometallics as Reaction Partners. Chem. Rev. 2011, 111, 1417-1492. [CrossRef] [PubMed]

2. Johansson Seechurn, C.C.C.; Kitching, M.O.; Colacot, T.J.; Snieckus, V. Palladium-Catalyzed Cross-Coupling: A Historical Contextual Perspective to the 2010 Nobel Prize. Angew. Chem. Int. Ed. 2012, 51, 5062-5085. [CrossRef] [PubMed]

3. Valente, C.; Çalimsiz, S.; Hoi, K.H.; Mallik, D.; Sayah, M.; Organ, M.G. The Development of Bulky Palladium NHC Complexes for the Most-Challenging Cross-Coupling Reactions. Angew. Chem. Int. Ed. 2012, 51, 3314-3332. [CrossRef] [PubMed]

4. Li, H.; Johansson Seechurn, C.C.C.; Colacot, T.J. Development of Preformed Pd Catalysts for Cross-Coupling Reactions, Beyond the 2010 Nobel Prize. ACS Catal. 2012, 2, 1147-1164. [CrossRef]

5. Mata, J.A.; Poyatos, M. Recent developments in the applications of palladium complexes bearing N-heterocyclic carbene ligands. Curr. Org. Chem. 2011, 15, 3309-3324. [CrossRef] 
6. Marion, N.; Nolan, S.P. Well-Defined N-Heterocyclic Carbenes-Palladium(II) Precatalysts for Cross-Coupling Reactions. Acc. Chem. Res. 2008, 41, 1440-1449. [CrossRef] [PubMed]

7. Boyarskiy, V.P.; Luzyanin, K.V.; Kukushkin, V.Y. Acyclic diaminocarbenes (ADCs) as a promising alternative to $\mathrm{N}$-heterocyclic carbenes (NHCs) in transition metal catalyzed organic transformations. Coord. Chem. Rev. 2012, 256, 2029-2056. [CrossRef]

8. Boyarskiy, V.P.; Luzyanin, K.V.; Kukushkin, V.Y. Palladium-(Acyclic Diaminocarbene) Species as Alternative to Palladium-(Nitrogen Heterocyclic Carbenes) in Cross-Coupling Catalysis. In Advances in Organometallic Chemistry and Catalysis; John Wiley \& Sons, Inc.: Hoboken, NJ, USA, 2013; Volume 53, pp. 145-155. ISBN 9788578110796.

9. Slaughter, L.M. Catalysis with Acyclic Aminocarbene Ligands: Alternatives to NHCs with Distinct Steric and Electronic Properties. In N-Heterocyclic Carbenes; Wiley-VCH Verlag GmbH \& Co. KGaA: Weinheim, Germany, 2014; pp. 499-524.

10. Michelin, R.A.; Pombeiro, A.J.L.; Guedes da Silva, M.F.C. Aminocarbene complexes derived from nucleophilic addition to isocyanide ligands. Coord. Chem. Rev. 2001, 218, 75-112. [CrossRef]

11. Slaughter, L.M. Acyclic Aminocarbenes in Catalysis. ACS Catal. 2012, 2, 1802-1816. [CrossRef]

12. Tskhovrebov, A.G.; Luzyanin, K.V.; Kuznetsov, M.L.; Sorokoumov, V.N.; Balova, I.A.; Haukka, M.; Kukushkin, V.Y. Substituent R-Dependent Regioselectivity Switch in Nucleophilic Addition of N -Phenylbenzamidine to Pd II and Pt II Complexed Isonitrile RN三C Giving Aminocarbene-Like Species. Organometallics 2011, 30, 863-874. [CrossRef]

13. Luzyanin, K.V.; Tskhovrebov, A.G.; Carias, M.C.; Guedes da Silva, M.F.; Pombeiro, A.J.L.; Kukushkin, V.Y. Novel Metal-Mediated ( $\mathrm{M}=\mathrm{Pd}, \mathrm{Pt}$ ) Coupling between Isonitriles and Benzophenone Hydrazone as a Route to Aminocarbene Complexes Exhibiting High Catalytic Activity $(\mathrm{M}=\mathrm{Pd})$ in the Suzuki-Miyaura Reaction. Organometallics 2009, 28, 6559-6566. [CrossRef]

14. Hübner, S.; de Vries, J.G.; Farina, V. Why Does Industry Not Use Immobilized Transition Metal Complexes as Catalysts? Adv. Synth. Catal. 2016, 358, 3-25. [CrossRef]

15. Corbet, J.P.; Mignani, G. Selected patented cross-coupling reaction technologies. Chem. Rev. 2006, 106, 2651-2710. [CrossRef] [PubMed]

16. Molnár, A. Efficient, Selective, and Recyclable Palladium Catalysts in Carbon-Carbon Coupling Reactions. Chem. Rev. 2011, 111, 2251-2320. [CrossRef] [PubMed]

17. Hou, Z.; Han, B. Coupling Reactions with Supported Ionic Liquid Catalysts. In Supported Ionic Liquids; Wiley-VCH Verlag GmbH \& Co. KGaA: Weinheim, Germany, 2014; pp. 233-250. ISBN 9783527331246.

18. Zhong, R.; Lindhorst, A.C.; Groche, F.J.; Kühn, F.E. Immobilization of N-Heterocyclic Carbene Compounds: A Synthetic Perspective. Chem. Rev. 2017, 117, 1970-2058. [CrossRef] [PubMed]

19. Ranganath, K.V.S.; Onitsuka, S.; Kumar, A.K.; Inanaga, J. Recent progress of N-heterocyclic carbenes in heterogeneous catalysis. Catal. Sci. Technol. 2013, 3, 2161-2181. [CrossRef]

20. Cazin, C.S.J. Recent advances in the design and use of immobilised $N$-heterocyclic carbene ligands for transition-metal catalysis. Comptes Rendus Chim. 2009, 12, 1173-1180. [CrossRef]

21. Mohammadi, E.; Movassagh, B. Polystyrene-resin supported N-heterocyclic carbene-Pd(II) complex based on plant-derived theophylline: A reusable and effective catalyst for the Suzuki-Miyaura cross-coupling reaction of arenediazonium tetrafluoroborate salts with arylboronic acids. J. Organomet. Chem. 2016, 822, 62-66. [CrossRef]

22. Mohammadi, E.; Movassagh, B. Synthesis of polystyrene-supported Pd(II)-NHC complex derived from theophylline as an efficient and reusable heterogeneous catalyst for the Heck-Matsuda cross-coupling reaction. J. Mol. Catal. A Chem. 2016, 418-419, 158-167. [CrossRef]

23. Bukhryakov, K.V.; Mugemana, C.; Vu, K.B.; Rodionov, V.O. Palladium N-Heterocyclic Carbene Precatalyst Site Isolated in the Core of a Star Polymer. Org. Lett. 2015, 17, 4826-4829. [CrossRef] [PubMed]

24. Jadhav, S.N.; Kumbhar, A.S.; Mali, S.S.; Hong, C.K.; Salunkhe, R.S. A Merrifield resin supported Pd-NHC complex with a spacer(Pd-NHC@SP-PS) for the Sonogashira coupling reaction under copper- and solvent-free conditions. New J. Chem. 2015, 39, 2333-2341. [CrossRef]

25. Wang, Z.; Yu, Y.; Zhang, Y.X.; Li, S.Z.; Qian, H.; Lin, Z.Y. A magnetically separable palladium catalyst containing a bulky $N$-heterocyclic carbene ligand for the Suzuki-Miyaura reaction. Green Chem. 2015, 17, 413-420. [CrossRef] 
26. Pahlevanneshan, Z.; Moghadam, M.; Mirkhani, V.; Tangestaninejad, S.; Mohammadpoor-Baltork, I.; Rezaei, S. Suzuki-Miyaura C-C coupling reactions catalysed by a homogeneous and nanosilica supported palladium(II) $\mathrm{N}$-heterocyclic carbene complex derived from 3,5-di(1-imidazolyl)pyridine. New J. Chem. 2015, 39, 9729-9734. [CrossRef]

27. Ghiaci, M.; Zarghani, M.; Khojastehnezhad, A.; Moeinpour, F. Preparation, characterization and first application of silica supported palladium- $N$-heterocyclic carbene as a heterogeneous catalyst for $\mathrm{C}-\mathrm{C}$ coupling reactions. RSC Adv. 2014, 4, 15496-15501. [CrossRef]

28. Karimi, B.; Marefat, M.R.; Hasannia, M.; Akhavan, P.F.; Mansouri, F.; Artelli, Z.; Mohammadi, F.; Vali, H. Imidazolyl-Functionalized Ordered Mesoporous Polymer from Nanocasting as an Effective Support for Highly Dispersed Palladium Nanoparticles in the Heck Reaction. ChemCatChem 2016, 8, 2508-2515. [CrossRef]

29. Conley, M.P.; Copéret, C.; Thieuleux, C. Mesostructured Hybrid Organic-Silica Materials: Ideal Supports for Well-Defined Heterogeneous Organometallic Catalysts. ACS Catal. 2014, 4, 1458-1469. [CrossRef]

30. Elhamifar, D.; Karimi, B.; Rastegar, J.; Banakar, M.H. Palladium-Containing Ionic Liquid-Based Ordered Mesoporous Organosilica: An Efficient and Reusable Catalyst for the Heck Reaction. ChemCatChem 2013, 5 , 2418-2424. [CrossRef]

31. Sarkar, S.M.; Yusoff, M.M.; Rahman, M.L. Mesoporous Silica MCM-41 Supported N-Heterocyclic Carbene-Pd Complex for Heck and Sonogashira Coupling Reactions. J. Chin. Chem. Soc. 2015, 62, 33-40. [CrossRef]

32. Martínez-Olid, F.; Andrés, R.; de Jesús, E.; Flores, J.C.; Gómez-Sal, P.; Heuzé, K.; Vellutini, L. Magnetically recoverable catalysts based on mono- or bis-(NHC) complexes of palladium for the Suzuki-Miyaura reaction in aqueous media: Two NHC-Pd linkages are better than one. Dalt. Trans. 2016, 45, 11633-11638. [CrossRef] [PubMed]

33. Yang, H.; Wang, Y.; Qin, Y.; Chong, Y.; Yang, Q.; Li, G.; Zhang, L.; Li, W. One-pot preparation of magnetic $\mathrm{N}$-heterocyclic carbene-functionalized silica nanoparticles for the Suzuki-Miyaura coupling of aryl chlorides: Improved activity and facile catalyst recovery. Green Chem. 2011, 13, 1352. [CrossRef]

34. Shang, N.; Gao, S.; Feng, C.; Zhang, H.; Wang, C.; Wang, Z. Graphene oxide supported N-heterocyclic carbene-palladium as a novel catalyst for the Suzuki-Miyaura reaction. RSC Adv. 2013, 3, 21863-21868. [CrossRef]

35. Park, J.H.; Raza, F.; Jeon, S.-J.; Kim, H.-I.; Kang, T.W.; Yim, D.; Kim, J.-H. Recyclable N-heterocyclic carbene/palladium catalyst on graphene oxide for the aqueous-phase Suzuki reaction. Tetrahedron Lett. 2014, 55, 3426-3430. [CrossRef]

36. Movahed, S.K.; Esmatpoursalmani, R.; Bazgir, A. N-Heterocyclic carbene palladium complex supported on ionic liquid-modified graphene oxide as an efficient and recyclable catalyst for Suzuki reaction. RSC Adv. 2014, 4, 14586. [CrossRef]

37. Widegren, J.A.; Finke, R.G. A review of the problem of distinguishing true homogeneous catalysis from soluble or other metal-particle heterogeneous catalysis under reducing conditions. J. Mol. Catal. A Chem. 2003, 198, 317-341. [CrossRef]

38. Schmidt, A.F.; Kurokhtina, A.A. Distinguishing between the homogeneous and heterogeneous mechanisms of catalysis in the Mizoroki-Heck and Suzuki-Miyaura reactions: Problems and prospects. Kinet. Catal. 2012, 53, 714-730. [CrossRef]

39. Crabtree, R.H. Resolving heterogeneity problems and impurity artifacts in operationally homogeneous transition metal catalysts. Chem. Rev. 2012, 112, 1536-1554. [CrossRef] [PubMed]

40. Ananikov, V.P.; Beletskaya, I.P. Toward the Ideal Catalyst: From Atomic Centers to a "Cocktail" of Catalysts. Organometallics 2012, 31, 1595-1604. [CrossRef]

41. Astakhov, A.V.; Khazipov, O.V.; Chernenko, A.Y.; Pasyukov, D.V.; Kashin, A.S.; Gordeev, E.G.; Khrustalev, V.N.; Chernyshev, V.M.; Ananikov, V.P. A New Mode of Operation of Pd-NHC Systems Studied in a Catalytic Mizoroki-Heck Reaction. Organometallics 2017, 36, 1981-1992. [CrossRef]

42. De Meijere, A.; Brase, S.; Oestreich, M. Metal-Catalyzed Cross-Coupling Reactions and More; De Meijere, A., Bräse, S., Oestreich, M., Eds.; Wiley-VCH Verlag GmbH \& Co. KGaA: Weinheim, Germany, 2014; ISBN 9783527655588.

43. Kashin, A.S.; Ananikov, V.P. Catalytic $\mathrm{C}-\mathrm{C}$ and $\mathrm{C}-$ heteroatom bond formation reactions: In situ generated or preformed catalysts? Complicated mechanistic picture behind well-known experimental procedures. J. Org. Chem. 2013, 78, 11117-11125. [CrossRef] [PubMed] 
44. Eremin, D.B.; Ananikov, V.P. Understanding active species in catalytic transformations: From molecular catalysis to nanoparticles, leaching, "Cocktails" of catalysts and dynamic systems. Coord. Chem. Rev. 2017, 346, 2-19. [CrossRef]

45. Gruttadauria, M.; Giacalone, F.; Noto, R. "Release and catch" catalytic systems. Green Chem. 2013, 15, 2608. [CrossRef]

46. Ohtaka, A.; Okagaki, T.; Hamasaka, G.; Uozumi, Y.; Shinagawa, T.; Shimomura, O.; Nomura, R. Application of "Boomerang" Linear Polystyrene-Stabilized Pd Nanoparticles to a Series of C-C Coupling Reactions in Water. Catalysts 2015, 5, 106-118. [CrossRef]

47. Pagliaro, M.; Pandarus, V.; Ciriminna, R.; Béland, F.; Demma Carà, P. Heterogeneous versus Homogeneous Palladium Catalysts for Cross-Coupling Reactions. ChemCatChem 2012, 4, 432-445. [CrossRef]

48. Mikhaylov, V.N.; Sorokoumov, V.N.; Balova, I.A. Polystyrene-supported diaminocarbene complexes of palladium(II): Synthesis, characterization and application as a precatalyst in Sonogashira-Hagihara and Suzuki-Miyaura cross coupling. Russ. Chem. Rev. 2017, 86, 459-473. [CrossRef]

49. Mikhaylov, V.N.; Sorokoumov, V.N.; Korvinson, K.A.; Novikov, A.S.; Balova, I.A. Synthesis and Simple Immobilization of Palladium(II) Acyclic Diaminocarbene Complexes on Polystyrene Support as Efficient Catalysts for Sonogashira and Suzuki-Miyaura Cross-Coupling. Organometallics 2016, 35, 1684-1697. [CrossRef]

50. Mikhailov, V.N.; Korvinson, K.; Sorokoumov, V.N. Chiral acyclic diaminocarbene complexes of palladium(II) immobilized on a polymeric support as promising catalysts of the Suzuki reaction. Russ. J. Gen. Chem. 2016, 86, 2473-2476. [CrossRef]

51. Boyarskiy, V.P.; Bokach, N.A.; Luzyanin, K.V.; Kukushkin, V.Y. Metal-Mediated and Metal-Catalyzed Reactions of Isocyanides. Chem. Rev. 2015, 115, 2698-2779. [CrossRef] [PubMed]

52. Crociani, B.; Boschi, T.; Belluco, U. Synthesis and reactivity of novel palladium(II)-isocyanide complexes. Inorg. Chem. 1970, 9, 2021-2025. [CrossRef]

53. Hashmi, A.S.K.; Lothschütz, C.; Böhling, C.; Rominger, F. From Isonitriles to Carbenes: Synthesis of New NAC - and NHC-Palladium(II) Compounds and Their Catalytic Activity. Organometallics 2011, 30, 2411-2417. [CrossRef]

54. Tšupova, S.; Rudolph, M.; Rominger, F.; Hashmi, A.S.K. Synthesis and Properties of Hydrazino Amino Acyclic Carbenes of Gold(I), Platinum(II), Palladium(II) and Rhodium(III). Adv. Synth. Catal. 2016, 358, 3999-4005. [CrossRef]

55. Zeiler, A.; Rudolph, M.; Rominger, F.; Hashmi, A.S.K. An Alternative Approach to PEPPSI Catalysts: From Palladium Isonitriles to Highly Active Unsymmetrically Substituted PEPPSI Catalysts. Chem. A Eur. J. 2015, 21, 11065-11071. [CrossRef] [PubMed]

56. Riedel, D.; Wurm, T.; Graf, K.; Rudolph, M.; Rominger, F.; Hashmi, A.S.K. From Isonitriles to Unsaturated NHC Complexes of Gold, Palladium and Platinum. Adv. Synth. Catal. 2015, 357, 1515-1523. [CrossRef]

57. Hashmi, A.S.K.; Lothschuetz, C.; Boehling, C.; Hengst, T.; Hubbert, C.; Rominger, F. Carbenes Made Easy: Formation of Unsymmetrically Substituted N-Heterocyclic Carbene Complexes of Palladium(II), Platinum(II) and Gold(I) from Coordinated Isonitriles and their Catalytic Activity. Adv. Synth. Catal. 2010, 352, 3001-3012. [CrossRef]

58. Ito, Y.; Hirao, T.; Saegusa, T. Heterocycle syntheses by diaminocarbene-palladium(II) complex intermediates. J. Organomet. Chem. 1977, 131, 121-131. [CrossRef]

59. Ito, Y.; Hirao, T.; Ohta, N.; Saegusa, T. Synthesis of ketenimine via (N-alkylimino)acylpalladium complex intermediate. Tetrahedron Lett. 1977, 18, 1009-1012. [CrossRef]

60. Ito, Y.; Hirao, T.; Saegusa, T. Synthetic reactions by complex catalysts. XXXVII. Novel and versatile method of carbodiimide synthesis oxidation of carbene palladium(II) complex with silver oxide. J. Org. Chem. 1975, 40, 2981-2982. [CrossRef]

61. Bruneau, A.; Roche, M.; Alami, M.; Messaoudi, S. 2-Aminobiphenyl Palladacycles: The "Most Powerful" Precatalysts in C-C and C-Heteroatom Cross-Couplings. ACS Catal. 2015, 5, 1386-1396. [CrossRef]

62. Timofeeva, S.; Kinzhalov, M.A.; Valishina, E.; Luzyanin, K.V.; Boyarskiy, V.P.; Buslaeva, T.M.; Haukka, M.; Kukushkin, V.Y. Application of palladium complexes bearing acyclic amino(hydrazido)carbene ligands as catalysts for copper-free Sonogashira cross-coupling. J. Catal. 2015, 329, 449-456. [CrossRef] 
63. Kinzhalov, M.A.; Boyarskiy, V.P.; Luzyanin, K.V.; Dolgushin, F.M.; Kukushkin, V.Y. Metal-mediated coupling of a coordinated isocyanide and indazoles. Dalt. Trans. 2013, 42, 10394. [CrossRef] [PubMed]

64. Otsuka, S.; Tatsuno, Y.; Ataka, K. Univalent palladium complexes. J. Am. Chem. Soc. 1971, 93, 6705-6706. [CrossRef] 